\title{
Evaluating the Therapeutic Potential and the Suitability of Neutron Beams Designed for Clinical BNCT
}

lan Postuma ( $\square$ ian.postuma@gmail.com )

INFN Sezione di Pavia https://orcid.org/0000-0001-9678-9277

Sara Gonzalez

CNEA

Maria Herrera

CONICET

Lucas Provenzano

CNEA

Michele Ferrarini

CNAO

Chiara Magni

UNIPV

Nicoletta Protti

UNIPV

Fatemi Setareh

INFN

Valerio Vercesi

INFN

Giuseppe Battistoni

INFN

Umberto Anselmi Tambur1ni

UNIPV

Yuan Hao Liu

Neuboron

Leena Kankaanranta

Helsinki University

Hanna Koivunoro

Neutron Therapeutics

Saverio Altieri

UNIPV

Silva Bortolussi 
INFN

\section{Research}

Keywords: BNCT BSA, UTCP, Epithermal neutron beam, Radiobiological figure of merit, out-of-beam dosimetry

Posted Date: October 28th, 2020

DOI: https://doi.org/10.21203/rs.3.rs-96688/v1

License: (c) (i) This work is licensed under a Creative Commons Attribution 4.0 International License. Read Full License 


\section{Evaluating the therapeutic potential and the suitability of neutron beams designed for clinical BNCT}

Research Article

Ian Postuma ${ }^{1}$ *, Sara J González ${ }^{2,3}$ Maria S Herrera ${ }^{3}$ Lucas Provenzano ${ }^{2,3}$ Michele Ferrarini ${ }^{4}$ Chiara Magni ${ }^{1,5}$ Nicoletta Protti ${ }^{1,5}$ Setareh Fatemi ${ }^{1}$ Valerio Vercesi ${ }^{1}$ Giuseppe Battistoni ${ }^{6}$ Umberto Anselmi Tamburini ${ }^{1,9}$ Yuan Hao Liu ${ }^{7,8}$ Leena Kankaanranta ${ }^{10}$ Hanna Koivunoro ${ }^{11}$ Saveio Altieri ${ }^{1,5}$ Silva Bortolussi ${ }^{1,5}$

1 Istituto Nazionale di Fisica Nucleare (INFN), Unit of Pavia, via Bassi 6, 27100 Pavia Italy

2 Comisión Nacional de Energía Atómica, CNEA, Buenos Aires, Argentina

3 Consejo Nacional de Investigaciones Científicas y Técnicas, CONICET, Buenos Aires, Argentina

4 Centro Nazionale di Adroterapia Oncologica, CNAO, strada campeggi 53, 27100 Pavia Italy

5 University of Pavia, Department of Physics, via Bassi 6, 27100 Pavia Italy

6 Istituto Nazionale di Fisica Nucleare (INFN), Unit of Milan, via Celoria 16, 20133 Milan, Italy

7 Neuboron Medtech, Nanjing, China

8 Nanjing University of Areonautics and Astronautics, Nanjing, China

9 University of Pavia, Department of Chemistry, via Taramelli 12, 27100 Pavia Italy

10 Helsinki University Clincial Hospital, HUCH, Helsinki, Finland

11 Neutron Therapeutics, Boston, USA

* E-mail: ian.postuma@gmail.com 
Abstract: The standard of neutron beam quality for Boron Neutron Capture Therapy (BNCT) of deep-seated tumours is currently defined by its physical characteristics in air: the epithermal neutron flux, the ratio of thermal and epithermal neutron flux, the fast neutron and photon dose contamination, and the beam collimation.

Traditionally, the beam design consists in tailoring a Beam Shaping Assembly (BSA) able to deliver a neutron beam with the recommended values of these figures of merit (FOMs).

This work investigated the possibility to produce an epithermal neutron beam able to guarantee the best clinical performance for deep-seated tumours, starting from a $5 \mathrm{MeV}, 30 \mathrm{~mA}$ proton beam coupled to a beryllium target. Different Beam Shaping Assemblies were designed using those physical FOMs which, however, were not enough to establish a clear ranking of the different beams, nor to describe their clinical relevance.

To go beyond this traditional approach, beams were then evaluated employing new criteria based on the dose distributions obtained in-phantom and on the calculation of the Uncomplicated Tumour Control Probability (UTCP). Such radiobiological FOM allows establishing the therapeutic potential of the beams. Moreover, we included the concept of suitability as a criterion to select the safest BSA design, calculating the in-patient out-of-beam dosimetry.

The clinical relevance of the selected beam was finally tested in the treatment planning of a clinical case treated at the FiR 1 beam in Finland, where several patients have safely and successfully received BNCT in the last years. Despite the selected beam does not comply with all the standard physical recommendations, it shows a therapeutic potential comparable and even better than that of FiR 1. This confirms that establishing the performance of a beam cannot rely only on its physical characteristics, but requires additional criteria able to predict the clinical outcome of a BNCT treatment.

J Rad Onc Inform 2014 X(X): XX-XX

doi: $10.5166 /$ jroi-X-X-XX

Authors have no conflicts to disclose.

Keywords: BNCT BSA • UTCP • Epithermal neutron beam • Radiobiological figure of merit • out-of-beam dosimetry

(C) Journal of Radiation Oncology Informatics.

\section{Introduction}

Boron Neutron Capture Therapy (BNCT) is a form of hadrontherapy that exploits the products of neutron capture reactions in ${ }^{10} \mathrm{~B}$ to treat neoplasms. The therapy is performed by targeting the tumour with a drug loaded with ${ }^{10} \mathrm{~B}$ and subsequently irradiating the volume with a thermal neutron field (i.e. $25 \mathrm{meV}$ neutrons). At this energy, the thermal neutron capture reaction ${ }^{10} B(n, \alpha){ }^{7} \mathrm{Li}$ has a high cross section (3837 b) and generates two high-LET, short-range charged particles, whose damage is localised in the proximity of cells that uptake ${ }^{10} \mathrm{~B}$. If boron concentration is sufficiently higher in the malignancy than in the normal tissues, it is possible to cause a selective lethal effect in tumour. The selectivity warranted by the biological distribution of boron makes BNCT a potential therapeutic option for disseminated or infiltrated neoplasms. Moreover, as the effect is due to highly biological effective radiation, BNCT is studied to treat recurrent or radio-resistant tumours. Many BNCT clinical trials have been performed worldwide with promising results, especially on head and neck cancer, cutaneous melanoma and brain tumours [1-3].

BNCT has been applied in institutions equipped with research nuclear reactors, which are neutron sources intense enough to ensure acceptable treatment times. Today neutron fluxes of the order of $10^{9} \mathrm{~cm}^{-2} \mathrm{~s}^{-1}$ can be produced with proton accelerators coupled with Be or Li targets (accelerator-based BNCT or ab-BNCT) [4]. Accelerators are more compact than reactors, easier to operate and maintain, and have no social acceptability issues, allowing their installation in health-care environments. This technology is giving a worldwide boost to new BNCT clinical 
facilities. Cyclotrons for BNCT are already in use for clinical trials in two centres in Japan [5]. Other accelerators, electrostatic or Radio Frequency Quadrupole (RFQ), are being developed and installed in Argentina, Japan, Russia, Finland, USA, UK, Israel [6-12].

The Italian National Institute of Nuclear Physics (INFN) designed and constructed an RFQ proton accelerator delivering a $5 \mathrm{MeV}, 30 \mathrm{~mA}$ proton beam in Continuous Wave (CW) mode [13]. The neutron yield at the Be target is $10^{14} \mathrm{~s}^{-1}$ with maximum neutron energy around $3.2 \mathrm{MeV}$ [14]. This spectrum must be tailored for BNCT, acting on moderation and collimation.

The optimal neutron beam for BNCT of deep-seated tumours has a spectrum peaked between 1 and $10 \mathrm{keV} \mathrm{[15-17],}$ requiring a Beam Shaping Assembly (BSA) to decrease neutron energy and to collimate the beam to minimize out-of-beam dose. The BSA is a typical element of the BNCT equipment, both for accelerators and reactors, and its characteristics depend on the initial neutron energy distribution (i.e. on the type of target and on the projectile energy) in the accelerator case. Presently, there is an increasing research work designing BSAs for ab-BNCT [12, 14, 18-25]. Hence, methods to compare and evaluate simulated beams are currently under discussion, introducing new simulation instruments, computational strategies and analysis criteria.

IAEA published the TecDoc-1223 in 2001 [26] describing the desired characteristics of the neutron beams for BNCT: values had been indicated for the minimum epithermal neutron flux, the minimum degree of collimation and the maximum gamma, thermal and fast neutron contamination in air (Table 1). Together with some in-phantom quantities [27], these FOMs until now have been the only guidelines to evaluate the suitability of neutron beams for BNCT. Presently, the idea is taking shape that a neutron beam should rather be evaluated using treatment planning calculations in real clinical cases for a reliable performance evaluation: beams that do not comply with the IAEA guidelines can still be effective for some tumours. Furthermore, a neutron beam for BNCT must also follow other important criteria: it must be safe for the whole body of the patient, and it must be tested for the radio-protection limitations according to the regulations in each country. In literature, few examples of more refined computational evaluations are available [28, 29].

\begin{tabular}{cc} 
Beam parameter & Recommended value \\
\hline \hline Epithermal Flux $\left(\phi_{\text {epi }}\right)$ & $>10^{9} \mathrm{~cm}^{-2} \mathrm{~s}^{-1}$ \\
$\frac{\dot{D}_{\text {fast }}}{\phi_{\text {epi }}}$ & $<2.0 \cdot 10^{-13} \mathrm{~cm}^{-2} \mathrm{~Gy}$ \\
$\frac{\phi_{t h}}{\phi_{e p i}}$ & $<0.05$ \\
$\frac{\dot{D}_{\gamma}}{\phi_{\text {epi }}}$ & $<2.0 \cdot 10^{-13} \mathrm{~cm}^{-2} \mathrm{~Gy}$ \\
$\frac{J}{\phi_{e p i}}$ & $>0.7$ \\
\hline \hline
\end{tabular}

Table 1. IAEA recommendations on beam quality. The suffix epi refers to energy range between $0.5 \mathrm{eV}$ and $10 \mathrm{keV}$.

In this work, beams obtained with different BSA configurations have been first evaluated according to the classic IAEA FOMs. For a more significant analysis, we then exploited a radiobiological figure of merit capable of classifying the beams according to their clinical performance. The same beams were then tested on a human 
whole-body phantom to evaluate the dose delivered to peripheral organs. The information retrieved from these evaluations led to the selection of the best BSA configuration. The candidate beam was finally used to simulate a treatment plan in a patient bearing head and neck tumour, one of the most promising targets in present BNCT clinical trials. The result of the radiobiological figure of merit in the treatment planning was compared with that of the original BNCT treatment.

The results of this set of evaluations show that free-beam, in-air parameters are unable to provide a clear ranking of the beams performance. To define the most adequate configuration other criteria are needed, more suitable for predicting the clinical outcome of a treatment, which is the relevant goal when designing a clinical facility.

\section{Materials and Methods}

Presently many reactor and accelerator-based neutron sources are available, all with characteristic neutron spectra, needing ad hoc BSA materials and geometrical configuration. For the INFN RFQ accelerator (5 MeV protons on Be target), the most performing moderating material has been proved to be aluminium fluoride $\left(\mathrm{AlF}_{3}\right)[30]$, which is available only in powder. To obtain a mechanically stable BSA, a dedicated study was carried out in Pavia to densify powders of $\mathrm{AlF}_{3}$, added with $\mathrm{LiF}$. An innovative sintering process has been devised and a dedicated machine has been designed and constructed, able to obtain, for the first time, aluminium fluoride elements with nearly $100 \%$ density, showing very good mechanical properties and resistance to radiation. AlF 3 doped with $\mathrm{LiF}_{\mathrm{F}}$ used throughout this work as the bulk moderation unit, to control the epithermal neutron flux and to lower as much as possible the fast $(>10 \mathrm{keV})$ and thermal $(<0.5 \mathrm{eV})$ neutron contamination. For simplicity, we do not present all the tested BSA materials and geometrical configurations. Instead, only five set-ups are reported to show the use of a radiobiological FOM as a criterion to select the most performing BSA.

\subsection{BSA material and geometrical composition}

Figure 1 shows the geometrical configurations used for this work. The geometrical set-up shown in Figure 1a has a reflector (black) that embeds the bulk moderating material (grey) which is subsequently embedded into shield 1, aimed at decreasing contamination. In the second set-up, Figure 1b, the bulk material embeds the target region, to guide neutrons with the desired energy towards the beam-port, while the reflecting material separates shield 2 from the bulk material. This buffer area prevents thermal neutrons from scattering in shield 2 back into the bulk material. At the same time, epithermal neutrons escaping from the bulk material are scattered back. This BSA has a larger shield 2, to further decrease beam contamination. Finally, the configuration shown in Figure 1c is a modification of $1 \mathrm{~b}$, aimed at increasing lateral neutron moderation and absorption. The cone shape of $1 \mathrm{~b}$ was reduced by increasing the amount of moderating material. To mitigate the unavoidable loss of flux, the volume of reflecting material around the bulk moderator was increased. The shape of reflector, lateral shielding and bulk moderator were optimised to reach a satisfactory epithermal neutron flux at the beam-port. The BSA in Figure 1c 
was also intended to better collimate the neutron beam.

Five different beams based on these three geometrical structures were selected. Table 2 describes the material composition and geometrical set-up of these BSAs.

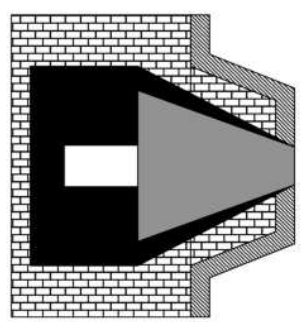

(a)

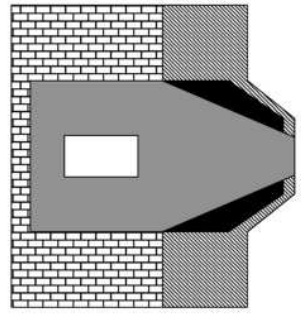

(b)

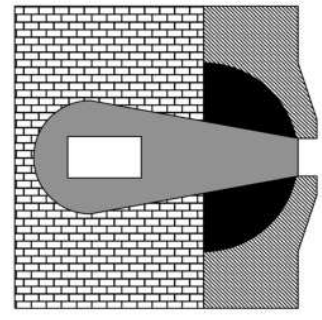

(c)

Figure 1. Schemes of the tested BSA structures. Each BSA can be separated in 4 different regions: The brick pattern is a first shielding material (shield 1), the black region is the reflector, the striped area represents a second shielding material (shield 2) and the grey area is the bulk moderating material. The central white box is the position of the target, neutrons are moderated and transported horizontally from the white box towards the beam port on the right. Lateral dimensions are $160 \mathrm{~cm}$ by $160 \mathrm{~cm}$, for the horizontal extension refer to Table 2 . The neutron source is located inside the white rectangle at the centre of the BSA and the proton beam is perpendicular to the direction of the neutron beam.

\begin{tabular}{c|c|c|c|c|c} 
BSA & Shield 1 & Shield 2 & Reflector & Bulk material composition (thickness [cm]) & Design \\
\hline \hline$\# 1$ & $\mathrm{~Pb}$ & $\mathrm{HW}+\mathrm{CLi}$ & $\mathrm{Pb}$ & $\mathrm{AlF}_{3}(35.5)+\mathrm{LiF}(1)+\mathrm{Bi}(.5)+\mathrm{Ti}(1)$ & $1 \mathrm{~b}$ \\
\hline$\# 2$ & $\mathrm{~Pb}$ & $\mathrm{C}+\mathrm{CH}_{2} \mathrm{Li}$ & $\mathrm{Pb}$ & $\mathrm{AlF}_{3}(35.5)+\mathrm{LiF}(1)+\mathrm{Bi}(.5)+\mathrm{Ti}(1)$ & $1 \mathrm{a}$ \\
\hline$\# 3$ & $\mathrm{~Pb}$ & $\begin{array}{l}\mathrm{C}+\mathrm{CLi}+ \\
\mathrm{CH}_{2} \mathrm{Li}+\mathrm{LiF}\end{array}$ & $\begin{array}{l}\mathrm{Pb}+ \\
\mathrm{LiF}\end{array}$ & $\mathrm{AlF}_{3}(35.75)+\mathrm{LiF}(1.5)+\mathrm{Bi}(.5)+\mathrm{Ti}(1)$ & $1 \mathrm{~b}$ \\
\hline$\# 4$ & $\mathrm{~Pb}$ & $\mathrm{C}+\mathrm{CLi}$ & $\mathrm{Pb}$ & $\mathrm{AlF}_{3}(35.5)+\mathrm{LiF}(1)+\mathrm{Bi}(.5)+\mathrm{Ti}(1)$ & $1 \mathrm{~b}$ \\
\hline$\# 5$ & $\mathrm{~Pb}$ & $\mathrm{LiF}+\mathrm{Teflon}$ & $\mathrm{CH}_{2} \mathrm{Li}$ & $\mathrm{AlF}_{3}$ with $3 \%$ mass of LiF $(37)$ & $1 \mathrm{c}$ \\
\hline
\end{tabular}

Table 2. Materials and design of some tested BSA setup. The last column refers to the BSA designs shown in Figure 1

\subsection{Evaluation of physical in-air parameters}

The described beams were tested against the Figures Of Merit (FOM) suggested by IAEA. Values of the FOMs were obtained by transporting neutrons with MCNP6 [31] from the beryllium target through the BSA to the beam port, where a surface tally with $6 \mathrm{~cm}$ radius was computed for the total neutron current (F1 tally type), epithermal neutron flux (F2 tally type), thermal neutron flux, fast neutron and gamma dose (F2 tally type combined with an FM card with appropriate tissue kerma factors). 


\subsection{Evaluation of the therapeutic potential of beams by a radiobiological FOM}

To introduce a criterion predicting the treatment outcome, we tested the beams in a phantom representing a human neck bearing a tumour. Head and neck $(\mathrm{H} \& \mathrm{~N})$ cancer is presently the principal target of clinical BNCT: promising clinical results have been obtained with reactors and BNCT trials for these tumours are ongoing at ab-BNCT facilities in Japan [1, 5]. The phantom is a cylinder (radius of $10 \mathrm{~cm}$ and height of $24 \mathrm{~cm}$ ) of mucosa, which is the tissue at risk in $\mathrm{H} \& \mathrm{~N}$ BNCT treatments. A $2 \mathrm{~cm}$ radius sphere centred $3 \mathrm{~cm}$ from the phantom equator surface represents the tumour. Boron concentration was assumed to be the standard in Finland treatments: 15 ppm in blood, which results in 30 ppm in mucosa and $52.5 \mathrm{ppm}$ in tumour [32].

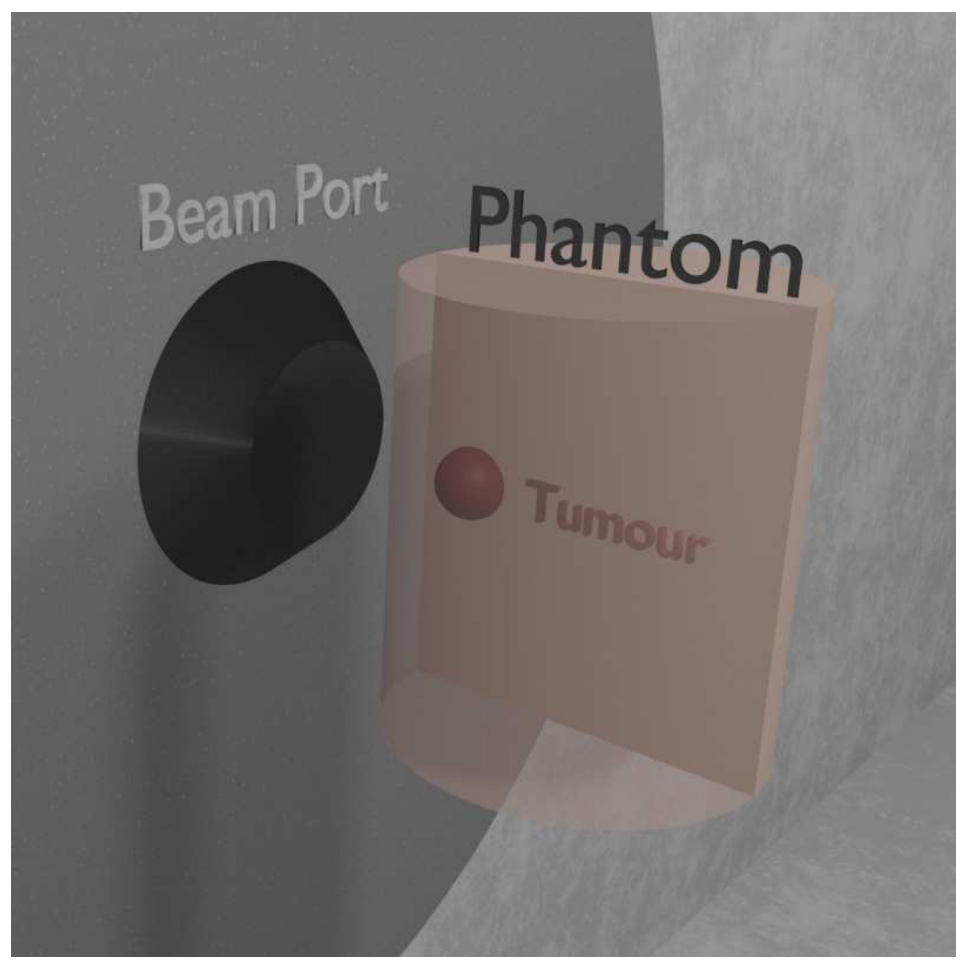

Figure 2. 3D view of the phantom simulated in front of the beam port, facing the neutron beam with the tumour region.

Figure 2 shows the simulated set-up, where the phantom is irradiated with a beam-to-phantom distance of $7.5 \mathrm{~cm}$, reproducing the average distance of patients from the beam port in clinical experience [33]. The dose was calculated with the photon iso-effective model [34]. To assess the therapeutic potential, we calculated the Uncomplicated Tumour Control Probability (UTCP) [33], defined as the probability to control the tumour without complication in the relevant healthy tissue, in this case, mucosa. UTCP is the product of the tumour Control Probability (TCP) and the complementary of Normal Tissue Complication Probability (1-NTCP). The closer this FOM is to 1, the highest is the probability to control the tumour without normal tissue complications. This criterion was used for the first time by Provenzano et al. [33] for the comparison of different clinical facilities, and it is proposed here 
as a criterion to select adequate beams among different candidates. UTCP was computed using TCP model for inhomogeneous dose distribution [33] and NTCP model that can predict mucositis of grade 3 or higher ( $\geq$ G3) after head and neck cancer radiotherapy with photons and BNCT [34]. With this model, it is possible to calculate the treatment time that maximizes UTCP.

\subsection{Evaluation of the beams suitability by out-of-beam dosimetry}

Besides the therapeutic potential, it is critical to select the safest beam for the patient, i.e. the one delivering the lowest dose to the organs outside the irradiation field. To study this property, the beams were tested using the anthropomorphic phantom MIRD [35, 36]. Equivalent dose was calculated with the prescription of ICRP report 116 [37]: weight for photon dose is 1 , for boron component is 20 and neutron dose has been weighted according to the function of energy described in the ICRP report 116. To compare the out-of-beam dose values with those found in literature, biologically weighted dose was also obtained by multiplying the different components by $\mathrm{RBE} / \mathrm{CBE}$ shown in Table 3. These doses were computed with MCNP6 using F4 tally type combined with kerma factors.

\begin{tabular}{l|cccc} 
Tissue & $\mathrm{RBE}_{\gamma}$ & $\mathrm{RBE}_{n}$ & $\mathrm{CBE}_{B}$ & $\begin{array}{c}10 \\
\mathrm{~B} \text { Concentration } \\
(\mu \mathrm{g} / \mathrm{g})\end{array}$ \\
\hline \hline Brain & 1 & 3.2 & 1.3 & 15 \\
Skin & 1 & 2.5 & 2.5 & 22.5 \\
Liver & 1 & 3.2 & 4.2 & 15 \\
Lung & 1 & 3.2 & 1.3 & 15 \\
Kidney & 1 & 3.2 & 1.3 & 75 \\
Bladder & 1 & 3.2 & 1.3 & 15 \\
Tumour & 1 & 2.2 & 5.3 & 52.5 \\
\hline \hline
\end{tabular}

Table 3. RBE and CBE factors employed to calculate biological dose in different tissues [38-40].

Boron concentration was assumed to be 15 ppm in all the normal tissues except for the skin and kidneys, set to absorb 22.5 ppm [41] and 75 ppm, respectively. Kidneys are known to uptake a higher boron concentration than other tissues due to excretion of BPA via the urinary system: pharmacokinetics studies performed in animals and humans using fluorinated BPA and PET imaging have been analysed [42, 43]. Concentration in kidneys is high shortly after the injection of the tracer, and then it decreases after about 1 hour to a value around 5 times higher than in other normal tissues. At the same time, the concentration in bladder increases. Bio-distribution studies in a big animal model [41] treated with a protocol equal to the clinical one (350 mg $/ \mathrm{kg}$ of BPA for 45 minutes) confirm the findings in the human studies. For this study, we thus assumed a boron concentration in kidney equal to $75 \mathrm{ppm}$. As shown in the PET images of the cited papers, a high boron concentration is expected in the urine after some time from BPA administration. However, the urinary bladder tissue absorbs a boron concentration similar to other normal tissues [44]. The dose delivered to the tissues due to the boron present in the urine is limited to the layer of urine adjacent to the organ walls with a thickness equal to the particles range, i.e. about 10 
micrometres. For this reason, boron in urine was neglected in the calculation of the dose delivered to the bladder, assumed to uptake $15 \mathrm{ppm}$ of boron.

The combination of therapeutic potential and suitability assessment allowed the ranking of the candidate beams, resulting in a clear selection of the best BSA design.

\subsubsection{Treatment Planning simulation}

The selected beam was finally used to simulate a BNCT treatment plan. The chosen clinical case is a Head and Neck cancer patient (squamous cell carcinoma) treated with BPA-mediated BNCT in Finland [32]. The performance of the selected beam is compared with that of FiR 1 in the real treatment.

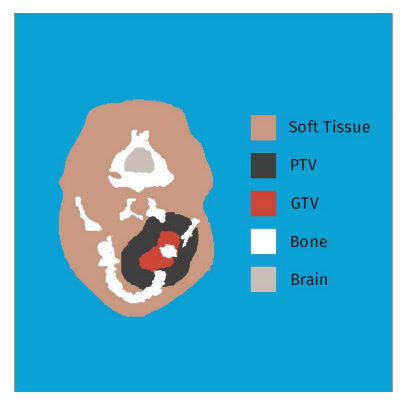

a)

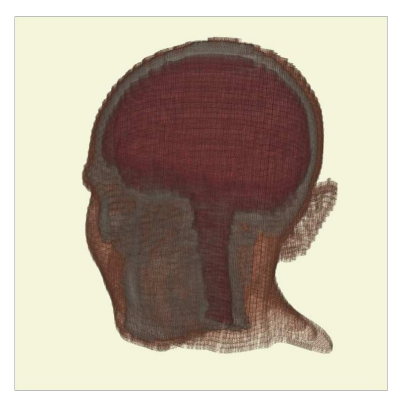

b)

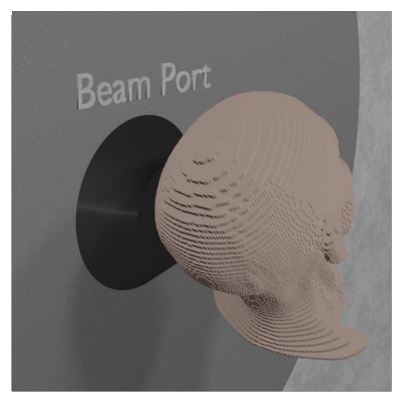

c)

Figure 3. Image a) shows a slice of the patient DICOM image segmented into 5 materials, which is then converted into a voxelized phantom by MultiCell as shown in image b). Image c) shows the TPS set-up as fed into the MCNP simulation.

MultiCell was used as the Treatment Planning System, to obtain the voxelized patient model shown in Figure $3 \mathrm{a}$ (segmented image) and in Figure 3b (3D representation), to set the two fractions treatment configuration and to produce the input for dose calculation by MCNP [45, 46]. Figure 3c shows the voxelized phantom positioned in front of the beam port. The dose-limiting point in mucosa used to calculate the optimum treatment time and maximum UTCP is the one selected by medical doctors in the real treatment. Based on the obtained irradiation time, photon iso-effective doses and the Dose Volume Histogram (DVH) were calculated in the contoured tumour volume. UTCP curve was computed as described by Provenzano et al [33].

\section{Results}

\subsection{Evaluation of physical in-air parameters}

Table 4 shows the results of the calculation of physical FOMs for each beam (Table 2 and Figure 1), compared to the recommended values. BSA \#1 and BSA \#4 ensure a lower gamma contamination while keeping a high neutron flux. This is mainly due to the use of heavy water and graphite, in shield 2 region, instead of materials containing hydrogen. BSA \#2 is the one with the lowest fast neutron dose contamination, while BSA \#3 is the one 
with the lowest gamma dose contamination. These beams show lower fast neutron dose contamination compared to BSA \#1 and BSA \#4, the main reason being that the shielding material contains hydrogen, which scatters low energy neutrons back into the beam. As a result, the epithermal neutron flux increases, but the epithermal energy spectrum is shifted towards energies lower than $1 \mathrm{keV}$. BSA \#5 is characterised by higher collimation (it is the only one complying with IAEA recommendation for this parameter) at the expense of lower epithermal neutron flux and the highest fast neutron dose contamination.

Table 4 shows how difficult it can be to evaluate a beam based on fixed values of physical properties. None of the tested beams is clearly optimal compared to the IAEA values. However, they may still be useful for patient treatment. To assess the suitability for clinical use, the beams were tested using the UTCP.

\begin{tabular}{l|ccccc} 
& $\begin{array}{c}\phi_{e p i} \\
10^{9}\left(\mathrm{~cm}^{-2} \mathrm{~s}^{-1}\right)\end{array}$ & $\begin{array}{c}\frac{\phi_{t h}}{\phi_{e p i}} \\
-\end{array}$ & $\begin{array}{c}\frac{\dot{D}_{F a s t}}{\phi_{e p i}} \\
10^{-13}\left(\mathrm{~cm}^{2} \mathrm{~Gy}\right)\end{array}$ & $\begin{array}{c}\frac{\dot{D}_{\gamma}}{\phi_{e p i}} \\
10^{-13}\left(\mathrm{~cm}^{2} \mathrm{~Gy}\right)\end{array}$ & $\begin{array}{c}\frac{J}{\phi_{e p i}} \\
-\end{array}$ \\
\hline \hline Recommended & $>1$ & $<0.05$ & $<2.0$ & $<2.0$ & $>0.7$ \\
\hline \hline BSA \#1 & 2.58 & 0.019 & 9.16 & 3.96 & 0.59 \\
BSA \#2 & 2.56 & 0.054 & 6.70 & 6.66 & 0.60 \\
BSA \#3 & 1.73 & 0.004 & 7.71 & 2.70 & 0.62 \\
BSA \#4 & 2.79 & 0.018 & 9.09 & 3.78 & 0.59 \\
BSA \#5 & 1.08 & 0.009 & 9.50 & 4.17 & 0.74 \\
\hline \hline
\end{tabular}

Table 4. IAEA FOM calculated for the BSAs listed in Table 2. The reported results have a relative error lower than $2 \%$.

\subsubsection{Radiobiological FOM}

Table 5 shows the evaluation of the UTCP on the cylindrical phantom, obtained by maximizing this FOM for each BSA configuration. With this evaluation, it is clear that BSA \#5 has the highest UTCP value, obtained from the highest TCP and lowest NTCP. All beams allow reasonable treatment times. To highlight the clinical relevance of UTCP evaluation, note that the dose D (the maximum dose to the healthy tissue at risk) is very close to the clinically prescribed dose of 6 Gy [47].

\begin{tabular}{|c|llll|c|ccccc|}
\hline BSA & $\begin{array}{l}\mathrm{T}_{i r r} \\
\text { (min) }\end{array}$ & UTCP TCP NTCP & $\mathrm{D}$ & \multicolumn{4}{|c|}{$\%$ Dose } \\
\hline \hline$\# 1$ & 10 & $\mathbf{0 . 4 1}$ & 0.5 & 0.19 & 5.79 & 0.61 & 0.06 & 0.06 & 0.27 \\
\hline$\# 2$ & 12.5 & $\mathbf{0 . 4 0}$ & 0.52 & 0.23 & 6.15 & 0.59 & 0.05 & 0.06 & 0.3 \\
\hline$\# 3$ & 20 & $\mathbf{0 . 4 4}$ & 0.57 & 0.23 & 5.81 & 0.62 & 0.07 & 0.06 & 0.25 \\
\hline$\# 4$ & 9.5 & $\mathbf{0 . 4 0}$ & 0.54 & 0.26 & 5.98 & 0.61 & 0.06 & 0.06 & 0.27 \\
\hline$\# 5$ & 24.5 & $\mathbf{0 . 4 7}$ & 0.58 & 0.18 & 5.59 & 0.61 & 0.09 & 0.06 & 0.23 \\
\hline \hline
\end{tabular}

Table 5. This table shows the results of the simulations with the cylindrical phantom. Each UTCP value is followed by its TCP, NTCP and irradiation time $\mathrm{T}_{\text {irr }}$. The dose column D shows the maximum dose to the healthy tissue, while the \% Dose section displays the different contributions to the dose D. 


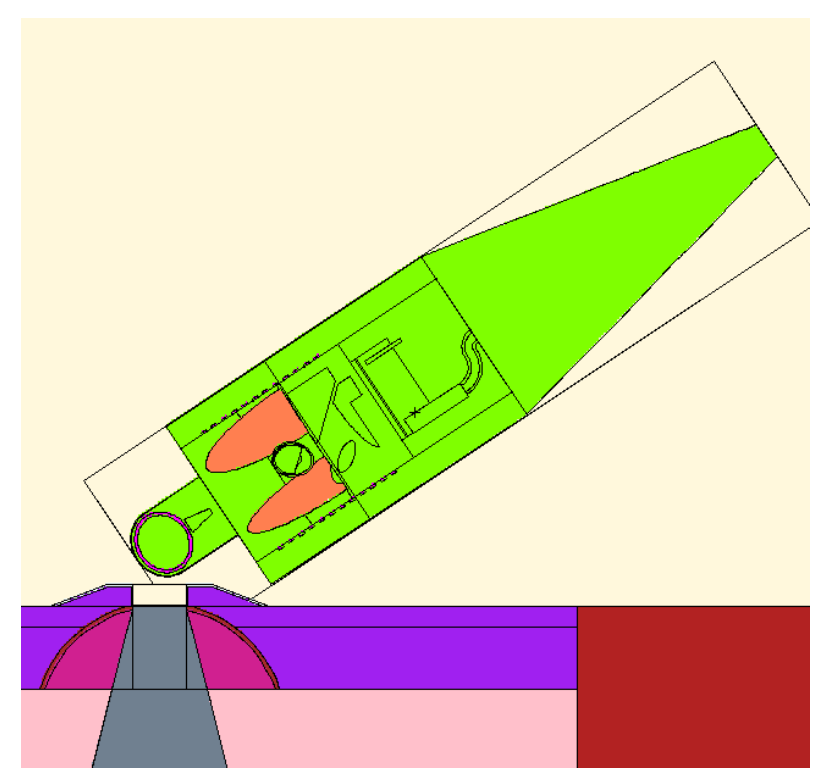

Figure 4. The image shows an MCNP plot of the MIRD phantom position that mimics a typical head irradiation in BNCT.

\subsubsection{Out-of-beam dosimetry}

The anthropomorphic male MIRD phantom, as shown in Figure 4 was positioned in a representative irradiation position for $\mathrm{H} \& \mathrm{~N}$ cancer treatment. For all beams, the biological weighted dose in Gy_Eq has been calculated in all the organs of the phantom. Figure 5 shows that BSA \#5 delivers doses significantly lower to the organs outside the irradiation field. In this respect, it is thus preferable.

This result together with the therapeutic potential is a clear demonstration that BSA \# 5 is clinically the most performing beam. Table 6 shows the dosimetry of this BSA on the organs of MIRD phantom. The values refer to the dose absorbed by a patient in a treatment time as calculated to maximise the UTCP: 24.5 minutes. The Table reports also the absorbed dose (Gy) separating the radiation components, and the weighted dose (Sv), calculated following the prescription of ICRP report 116 [48].

\subsubsection{Characteristics of the selected beam}

The BSA delivering BSA \#5 is showed in detail in Figure 6. The neutron spectrum averaged over the beam-port area $(6 \mathrm{~cm}$ radius circle) peaks around the desired energy of $10 \mathrm{keV}$. The flux decreases sharply when averaged over a circular ring going from $6 \mathrm{~cm}$ radius to $12 \mathrm{~cm}$ radius, the out-of-beam area (Figure 7 ). Figure 8 shows spectrum and flux behavior in-beam and out-of-beam. In Figure 8a, the logarithmic spectrum averaged over circular sectors of radii between 1 and $11 \mathrm{~cm}$, demonstrates that the spectral distribution is maintained below 6 $\mathrm{cm}$ (in-beam). Out of beam, the flux decreases with the radius, and the proportion of the spectrum components changes. Figure $8 \mathrm{~b}$ shows the distribution of the different spectral components as a function of the radius. Flux variation is within $20 \%$ inside the beam-port, and it sharply decreases out of beam. The thermal, epithermal and fast neutron components change at increasing radial distance. This is due to the different material composition of 


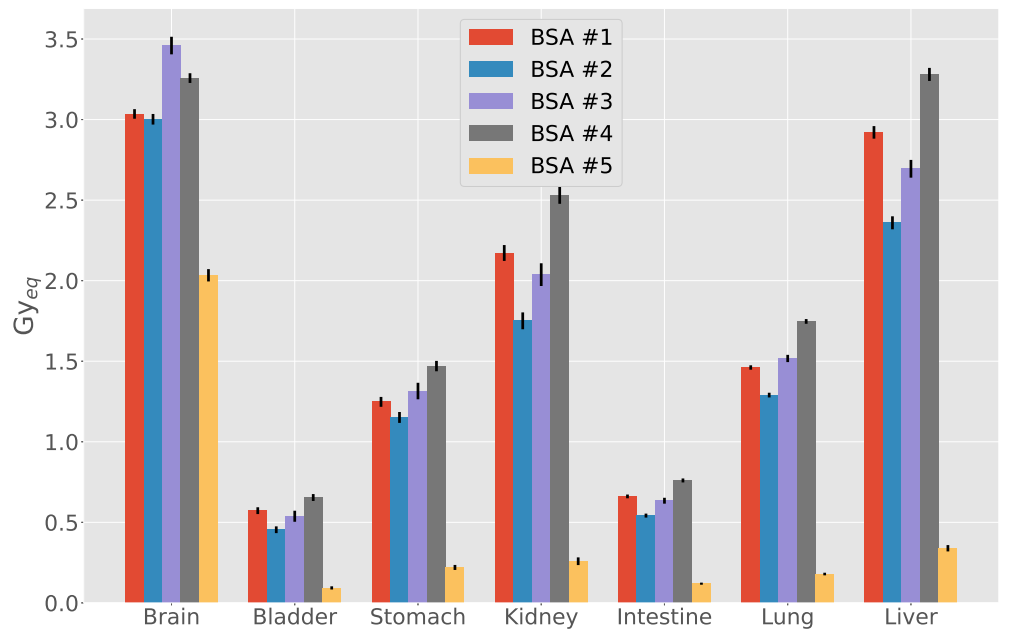

Figure 5. Comparison of out-of-beam dose evaluated in the MIRD phantom. Dose is evaluated for the treatment time, which is: 10 minutes for BSA \#1, 12.5 minutes for BSA \#2, 20 minutes for BSA \#3, 9.5 minutes for BSA \#4 and 24.5 minutes for BSA \#5.

\begin{tabular}{r||c|c|c|c|c|cc} 
Organ & $\begin{array}{c}\mathrm{D}_{N} \\
(\mathrm{~Gy})\end{array}$ & $\begin{array}{c}\mathrm{D}_{B} \\
(\mathrm{~Gy})\end{array}$ & $\begin{array}{c}\mathrm{D}_{H} \\
(\mathrm{~Gy})\end{array}$ & $\begin{array}{c}\mathrm{D}_{\gamma} \\
(\mathrm{Gy})\end{array}$ & $\begin{array}{c}\mathrm{D}_{W} \\
(\mathrm{~Sv})\end{array}$ & $\begin{array}{c}\mathrm{D}_{E q} \\
(\mathrm{~Gy} E \mathrm{Eq})\end{array}$ & $\begin{array}{c}\mathrm{Err} \\
(\mathrm{Gy} E \mathrm{Eq})\end{array}$ \\
\hline Brain & $1.06 \mathrm{E}-02$ & $1.21 \mathrm{E}-02$ & $4.14 \mathrm{E}-01$ & $4.38 \mathrm{E}-01$ & 5.11 & 2.03 & 0.04 \\
Bladder & $1.06 \mathrm{E}-03$ & $1.22 \mathrm{E}-03$ & $7.27 \mathrm{E}-04$ & $6.35 \mathrm{E}-02$ & 0.48 & 0.09 & 0.01 \\
Stomach & $1.51 \mathrm{E}-03$ & $1.74 \mathrm{E}-03$ & $9.99 \mathrm{E}-03$ & $1.49 \mathrm{E}-01$ & 0.77 & 0.22 & 0.02 \\
Kidneys & $1.21 \mathrm{E}-03$ & $1.39 \mathrm{E}-03$ & $2.99 \mathrm{E}-03$ & $1.10 \mathrm{E}-01$ & 2.26 & 0.26 & 0.02 \\
Intestine & $1.05 \mathrm{E}-03$ & $1.20 \mathrm{E}-03$ & $2.97 \mathrm{E}-03$ & $8.29 \mathrm{E}-02$ & 0.51 & 0.12 & 0.01 \\
Lungs & $1.88 \mathrm{E}-03$ & $2.16 \mathrm{E}-03$ & $2.90 \mathrm{E}-02$ & $5.61 \mathrm{E}-03$ & 0.80 & 0.18 & 0.01 \\
Liver & $1.33 \mathrm{E}-03$ & $1.53 \mathrm{E}-03$ & $7.55 \mathrm{E}-03$ & $1.15 \mathrm{E}-01$ & 1.12 & 0.34 & 0.02 \\
Heart & $1.87 \mathrm{E}-03$ & $2.15 \mathrm{E}-03$ & $2.22 \mathrm{E}-02$ & $1.66 \mathrm{E}-01$ & 0.95 & 0.28 & 0.02 \\
Spleen & $1.21 \mathrm{E}-03$ & $1.40 \mathrm{E}-03$ & $9.83 \mathrm{E}-03$ & $1.45 \mathrm{E}-01$ & 0.65 & 0.21 & 0.02 \\
Head & $5.51 \mathrm{E}-03$ & $6.31 \mathrm{E}-03$ & $1.99 \mathrm{E}-01$ & $3.72 \mathrm{E}-01$ & 2.82 & 1.15 & 0.02 \\
Thyroid & $4.83 \mathrm{E}-03$ & $5.54 \mathrm{E}-03$ & $9.14 \mathrm{E}-02$ & $2.68 \mathrm{E}-01$ & 2.32 & 0.68 & 0.07 \\
Testicles & $7.84 \mathrm{E}-04$ & $9.03 \mathrm{E}-04$ & $5.02 \mathrm{E}-04$ & $7.12 \mathrm{E}-02$ & 0.38 & 0.09 & 0.01 \\
Pancreas & $1.07 \mathrm{E}-03$ & $1.24 \mathrm{E}-03$ & $2.57 \mathrm{E}-03$ & $9.09 \mathrm{E}-02$ & 0.53 & 0.13 & 0.01 \\
Pharynx & $7.12 \mathrm{E}-03$ & $8.18 \mathrm{E}-03$ & $1.45 \mathrm{E}-01$ & $3.36 \mathrm{E}-01$ & 3.37 & 0.98 & 0.08 \\
Marrow & $1.45 \mathrm{E}-03$ & $1.66 \mathrm{E}-03$ & $4.91 \mathrm{E}-02$ & $1.60 \mathrm{E}-01$ & 0.80 & 0.35 & 0.01 \\
Adrenal & $9.11 \mathrm{E}-04$ & $1.05 \mathrm{E}-03$ & $1.04 \mathrm{E}-02$ & $1.01 \mathrm{E}-01$ & 0.48 & 0.16 & 0.04 \\
Thymus & $2.49 \mathrm{E}-03$ & $2.87 \mathrm{E}-03$ & $1.62 \mathrm{E}-02$ & $1.77 \mathrm{E}-01$ & 1.20 & 0.29 & 0.04 \\
Skin & $1.73 \mathrm{E}-03$ & $1.98 \mathrm{E}-03$ & $6.79 \mathrm{E}-02$ & $2.06 \mathrm{E}-01$ & 1.28 & 0.54 & 0.01 \\
Trunk & $1.43 \mathrm{E}-03$ & $1.65 \mathrm{E}-03$ & $1.81 \mathrm{E}-02$ & $1.46 \mathrm{E}-01$ & 0.74 & 0.24 & 0.00
\end{tabular}

Table 6. Absorbed dose (Gy), equivalent dose (Sv) and biologically weighted dose (Gy_Eq) to the organs of a MIRD phantom for BSA \#5. Dose is evaluated considering the whole treatment time of 25.4 minutes.

the BSA: on the beam axis $\mathrm{AlF}_{3}$ moderates the neutron spectra to a peak energy of $\approx 1 \mathrm{keV}$, while out of beam, the BSA contains a high concentration of hydrogen and consequently fast and epithermal neutrons are moderated towards thermal energies. 


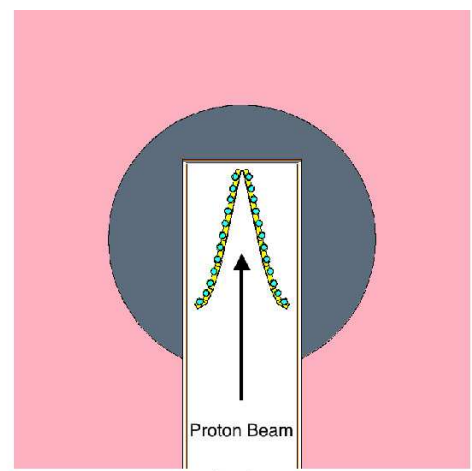

(a)

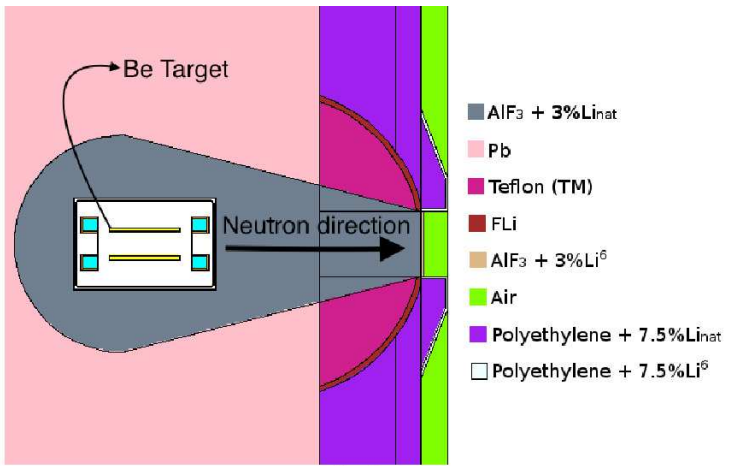

(b)

Figure 6. Geometrical configuration of the final BSA, the different colours represent the material composition of the BSA. Left: xy plane: the proton beam hits the target in the $\mathrm{z}$ direction. Right: xz plane. The target has a V-shape, to keep a compact design while removing the total heat generated [14].

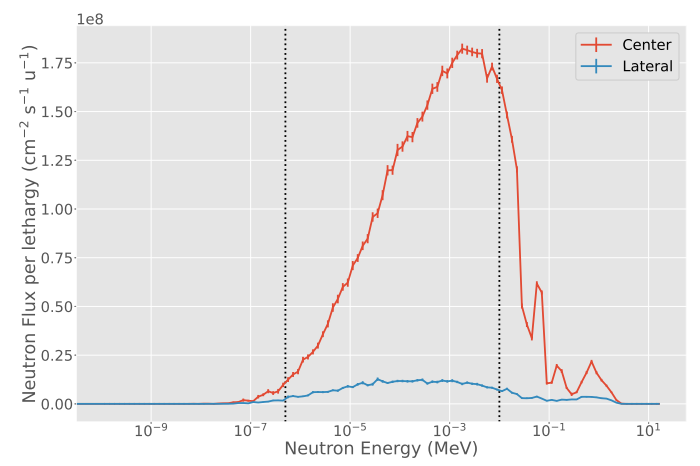

Figure 7. Final BSA energy spectra at the surface of the beam-port. Blue line: energy spectrum in a $6 \mathrm{~cm}$ radius disk, corresponding to the beam-port. Yellow line: spectrum in a ring with minimum radius of $6 \mathrm{~cm}$ and maximum radius of $12 \mathrm{~cm}$. The two vertical dotted lines separate thermal from epithermal energy ranges $\left(5 \cdot 10^{-7} \mathrm{MeV}\right)$ and epithermal from fast energy ranges $\left(10^{-2} \mathrm{MeV}\right)$.

\subsection{Treatment Planning}

The results of the treatment planning simulation for the optimum irradiation time and the corresponding data for

FiR 1 are shown in Table 7. Even though BSA \#5 only partially satisfies the recommendations of the IAEA FoMs, the maximum UTCP is higher than the one obtain with Fir 1 (a beam that complies with all recommendations). For approximately the same NTCP, the TCP for BSA \#5 is 0.56, for FiR 1 is 0.49, as shown in Figure 9. The higher TCP is a consequence of the higher minimum dose delivered to the tumour, as shown in Figure 10. In fact, BSA \#5 has a higher fast component than FiR 1, thus it is more penetrating. 

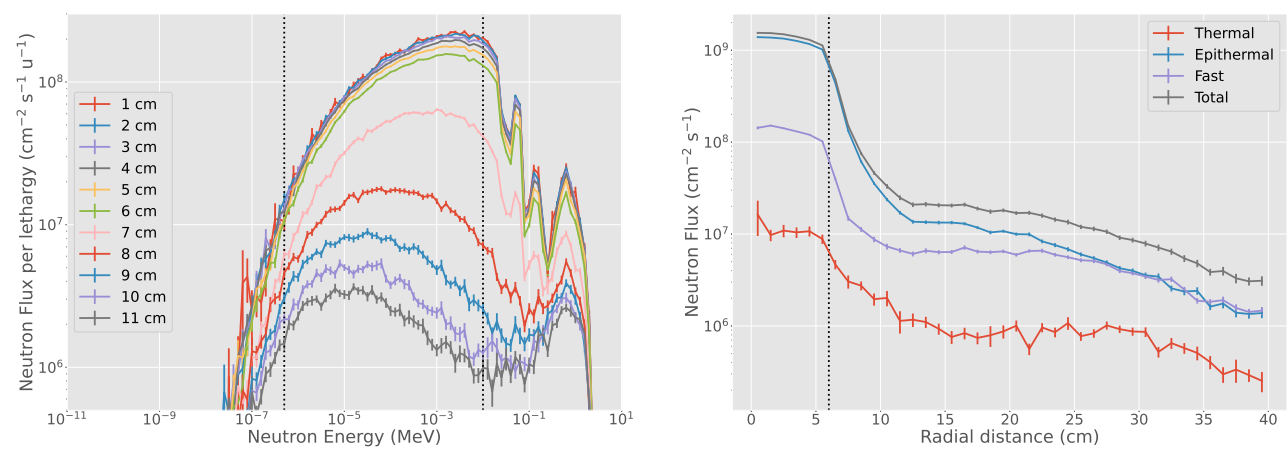

Figure 8. Neutron flux and energy spectra at the beam-port for BSA \#5. a) neutron spectra in concentric rings, with radii increasing by $1 \mathrm{~cm}$. The two vertical dotted lines separate thermal from epithermal energy ranges $\left(5 \cdot 10^{-7} \mathrm{MeV}^{-}\right.$and epithermal from fast energy ranges $\left(10^{-2} \mathrm{MeV}\right)$. b) radial neutron flux distribution from the centre of the beam-port in concentric rings going from $0 \mathrm{~cm}$ to $40 \mathrm{~cm}$ of radius. The vertical dotted line delimits the beam-port radius. Blue: thermal neutron flux $\left(\mathrm{E} \leq 5 \cdot 10^{-7} \mathrm{MeV}\right)$, orange: epithermal flux $\left(5 \cdot 10^{-7} \mathrm{MeV}<\mathrm{E} \leq 10^{-2} \mathrm{MeV}\right)$, green: fast flux ( $\left.10^{-2} \mathrm{MeV}<\mathrm{E}\right)$ and red: total neutron flux.

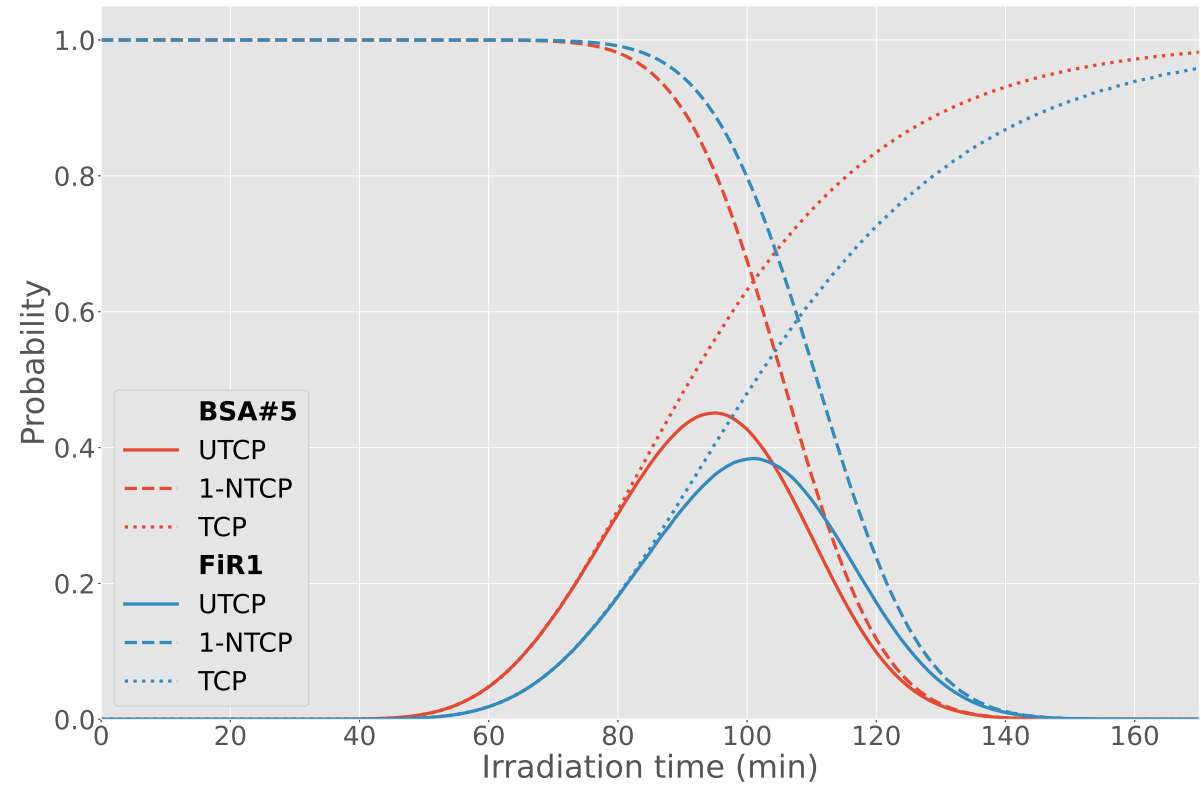

Figure 9. Comparison of the UTCP value for BSA \#5 and FiR 1 as a function of the irradiation time.

\section{Discussion}

In designing a clinical BNCT facility based on the accelerator built by INFN, the first step was to chose the BSA generating a beam suitable to treat deep-seated tumours. The free-beam in-air parameters proved to be a 


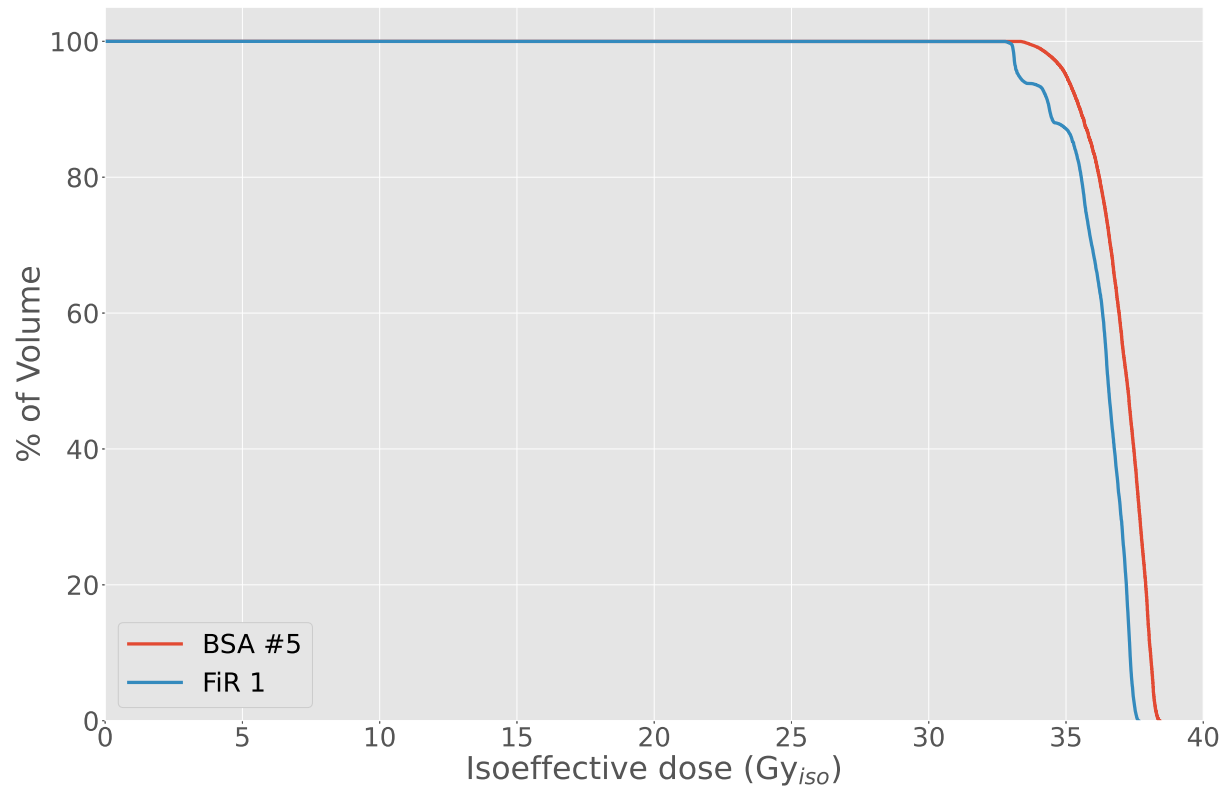

Figure 10. Comparison of the DVH obtained with BSA \#5 and FiR 1.

\begin{tabular}{|c|c|c|c|c|c|c|c|c|c|}
\hline Beam & $\begin{array}{l}\mathrm{T}_{i r r} \\
(\min )\end{array}$ & UTCP & $\mathrm{TCP}$ & NTCP & $\begin{array}{c}\mathrm{D} \\
(\mathrm{Gy}) \\
\end{array}$ & $(\mathrm{n}, \alpha)$ & $\begin{array}{r}\% \\
(\mathrm{n}, \mathrm{p}) \\
\end{array}$ & $\begin{array}{l}\text { Dose } \\
\text { and (n,n') }\end{array}$ & $\gamma$ \\
\hline $\mathrm{BSA} \# 5$ & 95 & 0.45 & 0.56 & 0.19 & 6.0 & 62 & & 8 & 30 \\
\hline FiR 1 & 101 & 0.38 & 0.49 & 0.22 & 5.4 & 74 & & 6 & 20 \\
\hline
\end{tabular}

Table 7. Results of the treatment planning simulation using BSA \#5 and corresponding values for FiR 1 . The maximum UTCP, TCP and NTCP is reported for the optimum irradiation time $\mathrm{T}_{\mathrm{irr}}$ of each beam. Dose $\mathrm{D}$ is the maximum absorbed dose to the dose-limiting point in healthy tissue and the \% Dose displays the different contributions to the dose D.

descriptive tool which however did not allow a ranking of the candidate beams. We then introduced the concept of therapeutic potential, i.e. the capacity to treat a deep-seated tumour without damaging the tissue at risk. For this assessment, we evaluated the UTCP, a radiobiological FOM which condenses the 3D dose distribution into one value related to the clinical outcome. This FOM allowed a rating of the 5 candidates. UTCP is particularly interesting because it is a prediction of the clinical outcome of the irradiation. To select the safest beam for the clinical treatment, we calculated the dose delivered to the other organs of the patient. This figure describes the suitability of a BNCT neutron beam. It is not possible to define a threshold above which the dose absorbed in an organ is considered too high for the treatment, because the priority is the clinical outcome of the tumour irradiation. Hence, we selected the configuration ensuring the minimum out-of-beam absorbed dose. We then compared the results with those obtained in similar irradiation position with both a designed ab-BNCT beam and with a reactor beam used in BNCT clinical applications (JRR4, Japan) [28, 49]. To this end, the components of 
absorbed dose were weighted using the RBE/CBE values and considering boron concentration listed in the cited documents. Figure 11 shows that the selected beam is comparable with the one designed by Herrera et al. [28], and delivers a dose to peripheral organs only slightly higher than the JRR4 beam.

Finally, we used the selected beam to compare its performance with the reference neutron facility FiR 1, in a clinical case that was successfully treated there. If clinical decision is in favour of selecting the treatment time that maximises the UTCP, the therapeutic potential of the selected beam - quantified by the maximum UTCP- is $15 \%$ higher than the one obtained for FiR 1. The real irradiation time of the H\&N cancer patient treated with FiR 1 was $110 \mathrm{~min}$, a value slightly higher than the one that maximises the UTCP. If we now simulate an irradiation time to equate the NTCP of the real treatment, the candidate beam achieves a TCP value $15 \%$ higher than the one obtained with FiR 1 in an irradiation time almost identical (i.e., a TCP value of 0.7 in 105 min for BSA \#5 VS a TCP value of 0.6 in 110 min for FiR 1 ).

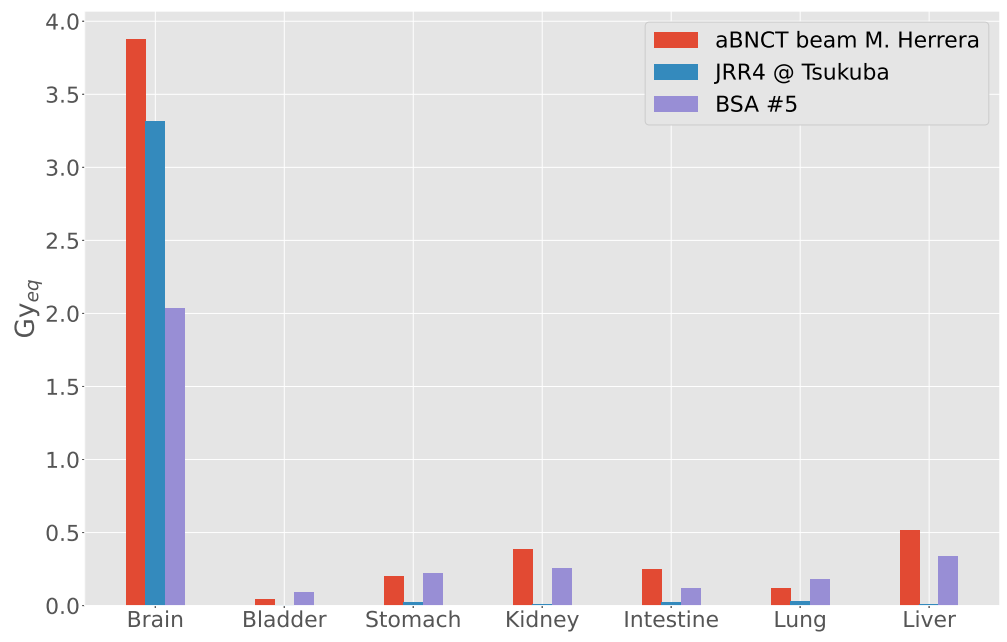

Figure 11. Out-of-beam dose evaluated in the MIRD phantom with BSA \#5, with a clinical reactor beam (JRR4) and with the ab-BNCT neutron beam designed by Herrera starting for $2.7 \mathrm{MeV}$ protons coupled with Li target [49].

\section{Conclusions}

The results obtained in this work confirm that it is possible to produce a neutron beam for clinical BNCT from the INFN RFQ, which accelerates a $5 \mathrm{MeV}, 30 \mathrm{~mA}$ proton beam on a Be target. The described optimisation allowed selecting an appropriate beam for clinical BNCT. The final beam satisfies only some of the IAEA recommendations. However, it proved to ensure a comparable clinical performance to that of our reference beam FiR 1 for H\&N treatment. 
This work proposes a comprehensive method to adequately evaluate the therapeutic potential and the suitability of BNCT beams. Our approach adds to the standard evaluation of the in-air physical parameters, the calculation of suitable radiobiological FOMs and out-of-field dose that directly account for the clinical performance and safety of these beams. An important discussion is now ongoing within the BNCT community on the necessity to establish common guidelines to evaluate BNCT beams. This is a non-trivial issue because the evaluation criteria strictly depend on the type of tumours that are addressed, i.e. shallow or deep-seated, and thus on the spectra that are preferable. Nevertheless, the biological effects of the overall dose distributions in patient must be taken into account. For this reason, radiobiological figures of merit such as TCP, NTCP and UTCP, give a deeper insight into the clinical effectiveness and outcome of the simulated treatment planning thus providing a robust criterion to predict the beam performance.

\section{List of abbreviations}

1. BNCT: Boron Neutron Capture Therapy

2. IAEA: International Atomic Energy Agency

3. TCP: Tumour Control Probability

4. NTCP: Normal Tissue Complication Probability

5. UTCP: Uncomplicated Tumour Control Probability

6. FOM: Figure Of Merit

7. RFQ: Radio Frequency Quadrupole

8. INFN: Istituto Nazionale di Fisica Nucleare

9. BSA: Beam Shaping Assembly

\section{Athical approval and consent to participate}

Not applicable

\section{Consent for publication}

Not applicable

\section{Availability of supporting data}

Not applicable 


\section{Competing Interests}

No competing interests

\section{Fundings}

Ministero degli affari esteri e della cooperazione internazionale (MAECI) grant PGR00710

\section{Author contributions}

IP adapted the neutron source in the beryllium target and validated it using experimental results; performed the simulations on BSA proposing all the described configurations; made the evaluations necessary to select the best beams (in air, in phantom). He wrote the manuscript (together with SB). SJG guided the treatment planning model and the discussion about the criteria to be used to improve the evaluation method. MSH started a deeper analysis of a simulated beam and proposed new figures of merit used in this work. LP helped in the treatment planning calculations. MF is expert in radioprotection and guided the development of beam \#5. CM performed the radioprotection dosimetric study in the air of the irradiation room. NP and SF collaborated to the discussion about the dosimetry and the radiation background around the irradiation position. VV and GB participated in the scientific discussion and helped with reviewing the written English. UAT developed the bulk moderating material which characterises the main moderating material in the simulations. Y-HL participated in the discussion about the new figures of merit to be used to better evaluated the designed beam. LK and HK shared the BNCT clinical case and participated in the evaluation of the TP simulations. SA participated in the study design and reviewed the results. SB supervised this work, contributed to the study design, helped in the treatment planning calculation, guided the advancements of the work and the optimisation of the beam according to the different chosen criteria, wrote the manuscript (together with IP).

\section{Acknowledgements}

This work has been carried out in the frame of INFN project BEAT_PRO, and in the NEU_BEAT project, funded by Italian Ministry of Foreign Affairs and International Cooperation in the 2016-2018 scheme of the Scientific and Technological Cooperation Agreement between Italy and China.

\section{References}

\section{References}


[1] Koivunoro H, Kankaanranta L, Seppälä T, Haapaniemi A, Mäkitie A and Joensuu H 2019 Radiotherapy and Oncology $137153-158$

[2] Menéndez P, Pereira M, Casal M, González S, Feld D, Santa Cruz G, Kessler J, Longhino J, Blaumann H, Rebagliati R J et al. 2009 Applied Radiation and Isotopes 67 S50-S53

[3] Lan T L, Chou F I, Lin K H, Pan P S, Lee J C, Huang W S, Liu Y M, Chao Y and Chen Y W 2020 Applied Radiation and Isotopes 160109105

[4] Rassow J and Sauerwein W 2012 Prescribing, recording and reporting of bnct Neutron Capture Therapy ed Sauerwein W, Wittig A, Moss R and Nakagawa Y (Springer Berlin Heidelberg) pp 277-285 ISBN 978-3-642$31333-2$

[5] Suzuki M 2019 International journal of clinical oncology 1-8

[6] Kreiner A, Vento V T, Levinas P, Bergueiro J, Di Paolo H, Burlon A, Kesque J, Valda A, Debray M, Somacal $\mathrm{H}$ et al. 2009 Applied Radiation and Isotopes 67 S266-S269

[7] Kumada H, Matsumura A and Sakurai H 2011 New challenge for advanced bnct in university of tsukuba. in the front edge of bnct development Proceedings of Sixth Young Researchers BNCT Meeting pp 132-136

[8] Aleynik V, Burdakov A, Davydenko V, Ivanov A, Kanygin V, Kuznetsov A, Makarov A, Sorokin I and Taskaev S 2011 Applied Radiation and Isotopes 69 1635-1638

[9] Savolainen S, Kortesniemi M, Timonen M, Reijonen V, Kuusela L, Uusi-Simola J, Salli E, Koivunoro H, Seppälä T, Lönnroth N et al. 2013 Physica Medica 29 233-248

[10] Kwan J, Anderson O, Reginato L, Vella M and Yu S 1995 Nuclear Instruments and Methods in Physics Research Section B: Beam Interactions with Materials and Atoms 99 710-712

[11] Allen D A, Beynon T D, Green S and James N D 1999 Medical Physics 26 77-82

[12] Halfon S, Paul M, Arenshtam A, Berkovits D, Bisyakoev M, Eliyahu I, Feinberg G, Hazenshprung N, Kijel D, Nagler A et al. 2011 Applied Radiation and Isotopes 69 1654-1656

[13] Mathot S 2004 LNL TRASCO-note

[14] Esposito J, Colautti P, Fabritsiev S, Gervash A, Giniyatulin R, Lomasov V, Makhankov A, Mazul I, Pisent A, Pokrovsky A et al. 2009 Applied Radiation and Isotopes 67 S270-S273

[15] Farías R O, Bortolussi S, Menéndez P R and González S J 2014 Physica Medica 30 888-897

[16] Yanch J C, Zhou X L and Brownell G L 1991 Radiation Research 126 1-20

[17] Bisceglie E, Colangelo P, Colonna N, Santorelli P and Variale V 2000 Physics in Medicine and Biology 4549

[18] Wang C K C and Moore B R 1994 Medical Physics 21 1633-1638

[19] Allen D and Beynon T 1995 Physics in Medicine and Biology 40807

[20] Blackburn B W, Yanch J C and Klinkowstein R E 1998 Medical Physics 25 1967-1974

[21] Lee C and Zhou X L 1999 Nuclear Instruments and Methods in Physics Research Section B: Beam Interactions with Materials and Atoms 152 1-11

[22] Howard W, Grimes S, Massey T, Al-Quraishi S, Jacobs D, Brient C and Yanch J 2001 Nuclear Science and 
Engineering 138 145-160

[23] Burlon A, Kreiner A, Valda A, Minsky D, Somacal H, Debray M and Stoliar P 2005 Nuclear Instruments and Methods in Physics Research Section B: Beam Interactions with Materials and Atoms 229 144-156

[24] Kobayashi T, Bengua G, Tanaka K and Nakagawa Y 2007 Physics in Medicine and Biology 52645

[25] Ceballos C, Esposito J, Agosteo S, Colautti P, Conte V, Moro D and Pola A 2011 Applied Radiation and Isotopes 69 1660-1663

[26] Rorer D, Wambersie G, Whitmore G, Zamenhof R, Levin V, Andreo P and Dodd D 2001 IAEA, 2001 (8) $75-77$

[27] Sakamoto S, Kiger III W and Harling O 1999 Medical Physics 26 1979-1988

[28] Herrera M, González S, Minsky D and Kreiner A 2013 Physica Medica 29 436-446

[29] Capoulat M and Kreiner A 2016 Physica Medica

[30] IPostuma 2016 Clinical application of accelerator-based Boron Neutron Capture Therapy: optimisation of procedures, tailoring of a neutron beam and evaluation of its dosimetric performance. Ph.D. thesis University of Pavia

[31] Goorley T, James M, Booth T, Brown F, Bull J, Cox L J, Durkee J, Elson J, Fensin M, Forster R A, Hendricks J, Hughes H G, Johns R, Kiedrowski B, Martz R, Mashnik S, McKinney G, Pelowitz D, Prael R, Sweezy J, Waters L, Wilcox T and Zukaitis T 2012 Nuclear Technology 180 298-315

[32] Kankaanranta L, Seppälä T, Koivunoro H, Saarilahti K, Atula T, Collan J, Salli E, Kortesniemi M, Uusi-Simola J, Välimäki P, Mäkitie A, Seppänen M, Minn H, Revitzer H, Kouri M, Kotiluoto P, Seren T, Auterinen I, Savolainen S and Joensuu H 2012 International Journal of Radiation Oncology*Biology*Physics 82 e67 - e75

[33] Provenzano L, Koivunoro H, Postuma I, Longhino J, Boggio E, Farías R, Bortolussi S and González S 2019 Physica Medica 679 - 19 ISSN 1120-1797

[34] González S J, Pozzi E C C, Hughes A M, Provenzano L, Koivunoro H, Carando D G, Thorp S I, Casal M R, Bortolussi S, Trivillin V A, Garabalino M A, Curotto P, Heber E M, Cruz G A S, Kankaanranta L, Joensuu $\mathrm{H}$ and Schwint A E 2017 Physics in Medicine E Biology 62 7938-7958

[35] Eckerman K, Cristy M and Ryman J 1996 Oak Ridge, TN: Oak Ridge National Laboratory

[36] Krstić D and Nikezić D 2007 Computer Physics Communications 176 33-37

[37] ICRP I 2010 Conversion Coefficients for Radiological Protection Quantities for External Radiation Exposures

[38] Suzuki M, Masunaga S I, Kinashi Y, Takagaki M, Sakurai Y, Kobayashi T and Ono K 2000 Cancer Science 91 1058-1064

[39] Coderre J A, Turcotte J C, Riley K J, Binns P J, Harling O K and Kiger W 2003 Technology in cancer research \& treatment 2 355-375

[40] Kiger J L, Kiger III W S, Riley K J, Binns P J, Patel H, Hopewell J W, Harling O K, Busse P M and Coderre J A 2008 Radiation research $\mathbf{1 7 0} 60-69$

[41] Farías R, Garabalino M, Ferraris S, Santa María J, Rovati O, Lange F, Trivillin V, Monti Hughes A, Pozzi E, 
Thorp S et al. 2015 Medical Physics 42 4161-4173

[42] Hanaoka K, Watabe T, Naka S, Kanai Y, Ikeda H, Horitsugi G, Kato H, Isohashi K, Shimosegawa E and J H 2014 EJNMMI Res 470

[43] Shimosegawa E, Isohashi K, Naka S, Horitsugi G and J H 2016 Ann Nucl Med 30749

[44] Kono Y, Kurihara H, Kawamoto H, Yasui N, Honda N, Igaki H and Itami J 2017 Acta Radiologica 58 1094-1100

[45] Farias R O and González S J 2012 Proceedings of the 15th international congress on neutron capture therapy, Tsukuba, Japan 148-150

[46] Farias R O 2015 Dosimetría y modelado computacional para irradiaciones extracorpóreas en humanos en el marco de la Terapia por Captura Neutrónica en Boro - PhD thesis - Buenos Aires, Argentina Ph.D. thesis Universidad Nacional de General San Martin, Comision Nacional de Energia Atomica, Istituto de Tecnologia

[47] H K 2012 Dosimetry and dose planning in boron neutron capture therapy: Monte Carlo studies Ph.D. thesis University of Helsinki

[48] Petoussi-Henss N, Bolch W, Eckerman K, Endo A, Hertel N, Hunt J, Pelliccioni M, Schlattl H and Zankl M 2010 Annals of the ICRP 40 1-257

[49] Herrera M 2014 Simulación computacional de la producción de flujos neutrónicos y planificación de tratamiento para la Terapia por Captura Neutrónica en Boro con aceleradores Ph.D. thesis Universidad Nacional de General San Martin, Comision Nacional de Energia Atomica, Istituto de Tecnologia 


\section{Figures}

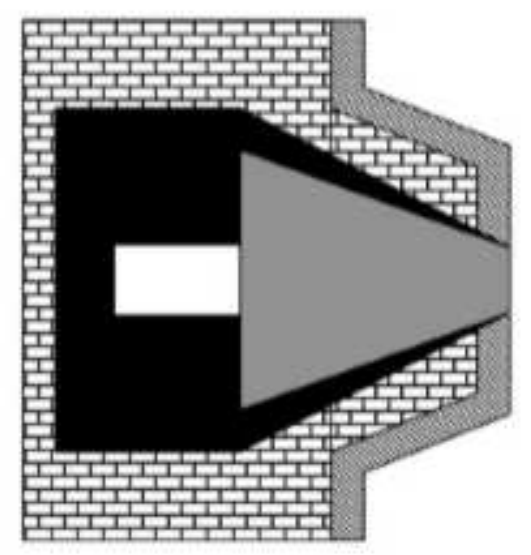

(a)

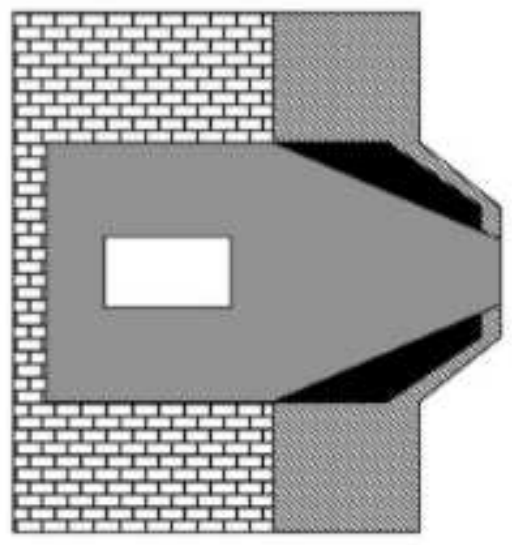

(b)

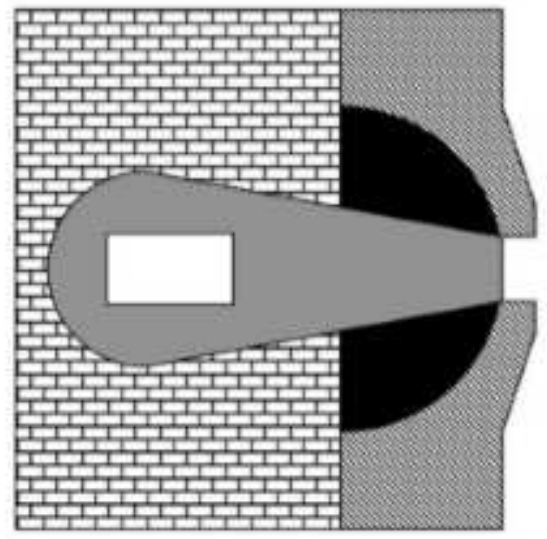

(c)

\section{Figure 1}

Schemes of the tested BSA structures. Each BSA can be separated in 4 different regions: The brick pattern is a first shielding material (shield 1), the black region is the reflector, the striped area represents a second shielding material (shield 2) and the grey area is the bulk moderating material. The central white box is the position of the target, neutrons are moderated and transported horizontally from the white box towards the beam port on the right. Lateral dimensions are $160 \mathrm{~cm}$ by $160 \mathrm{~cm}$, for the horizontal extension refer to Table 2. The neutron source is located inside the white rectangle at the centre of the BSA and the proton beam is perpendicular to the direction of the neutron beam. 


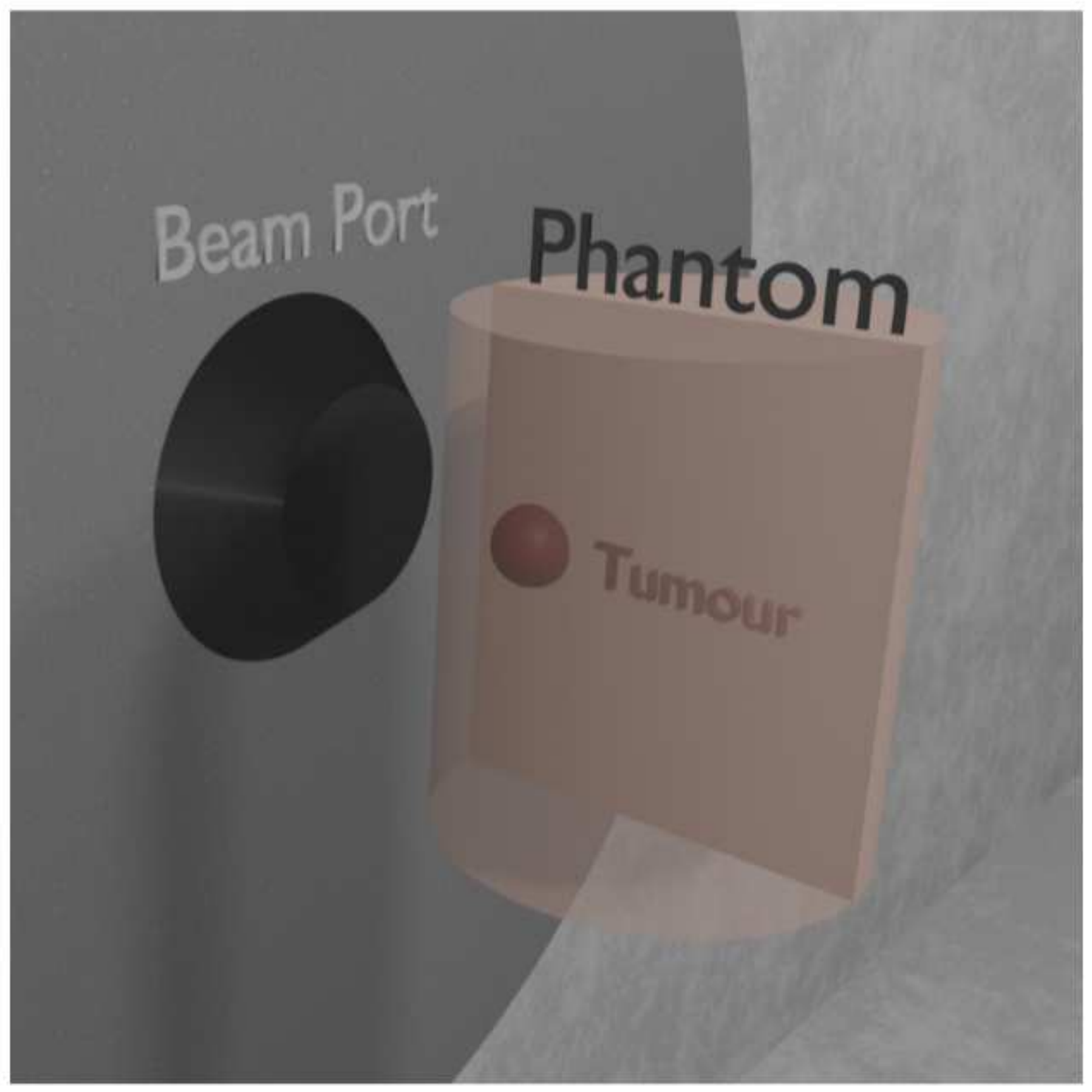

Figure 2

$3 \mathrm{D}$ view of the phantom simulated in front of the beam port, facing the neutron beam with the tumour region. 


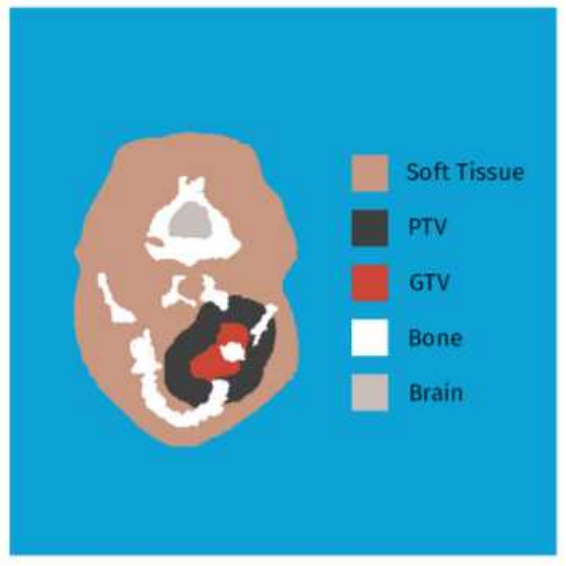

a)

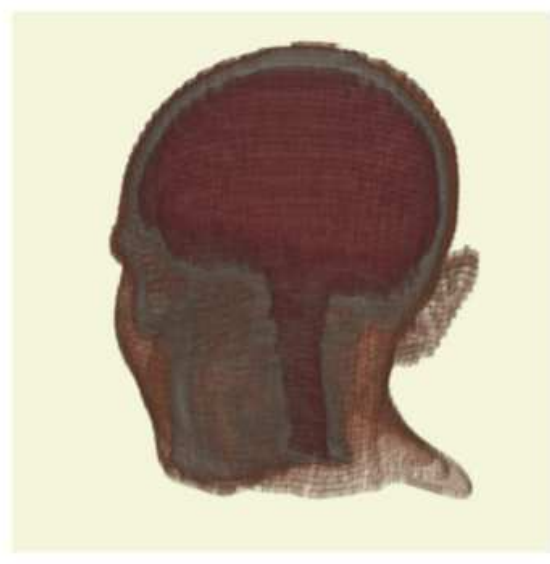

b)

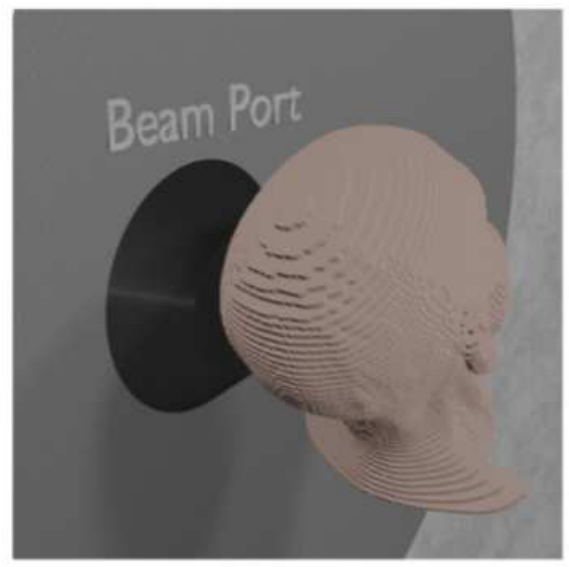

c)

\section{Figure 3}

Image a) shows a slice of the patient DICOM image segmented into 5 materials, which is then converted into a voxelized phantom by MultiCell as shown in image b). Image $c$ ) shows the TPS set-up as fed into the MCNP simulation. 


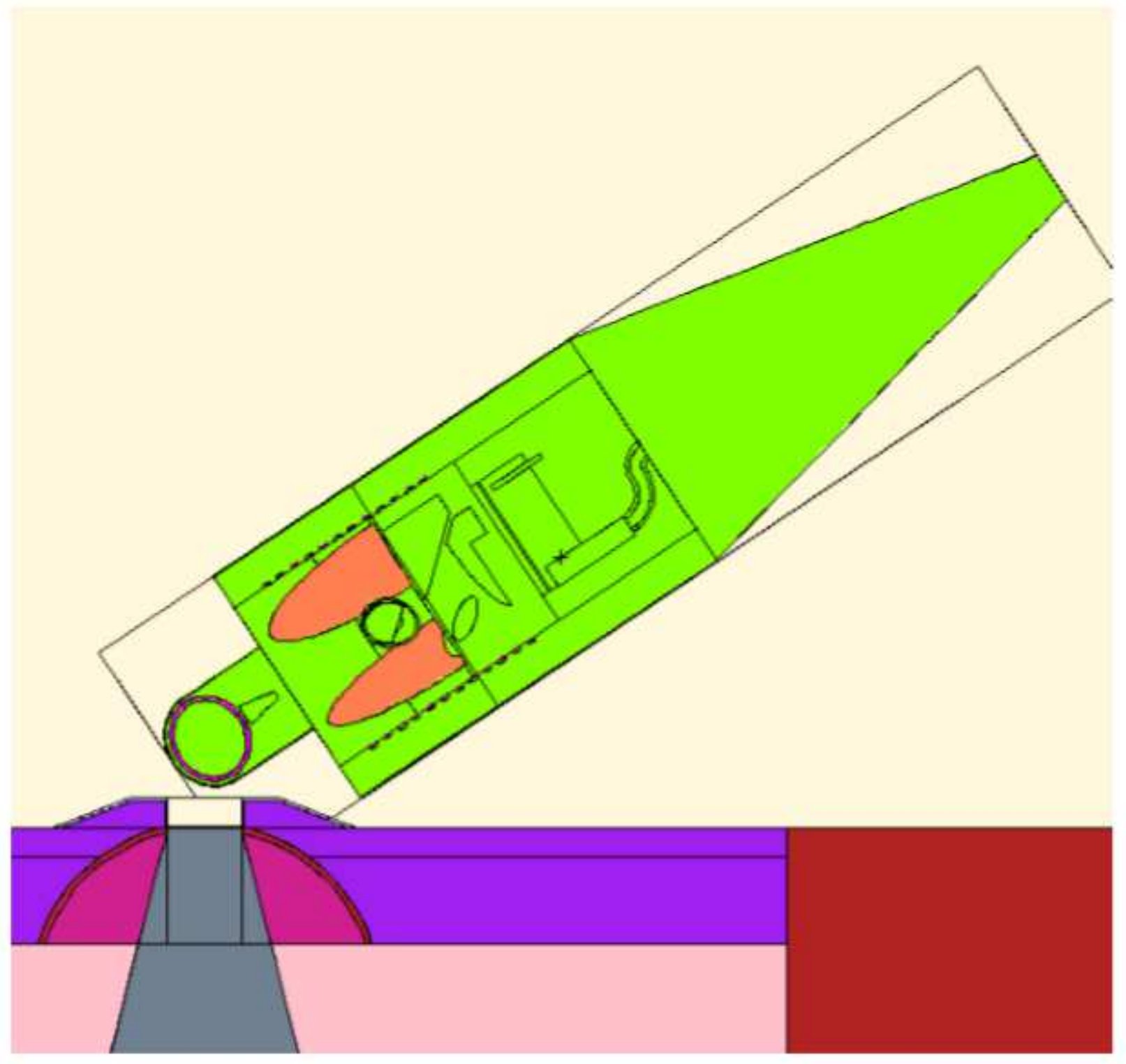

Figure 4

The image shows an MCNP plot of the MIRD phantom position that mimics a typical head irradiation in BNCT. 


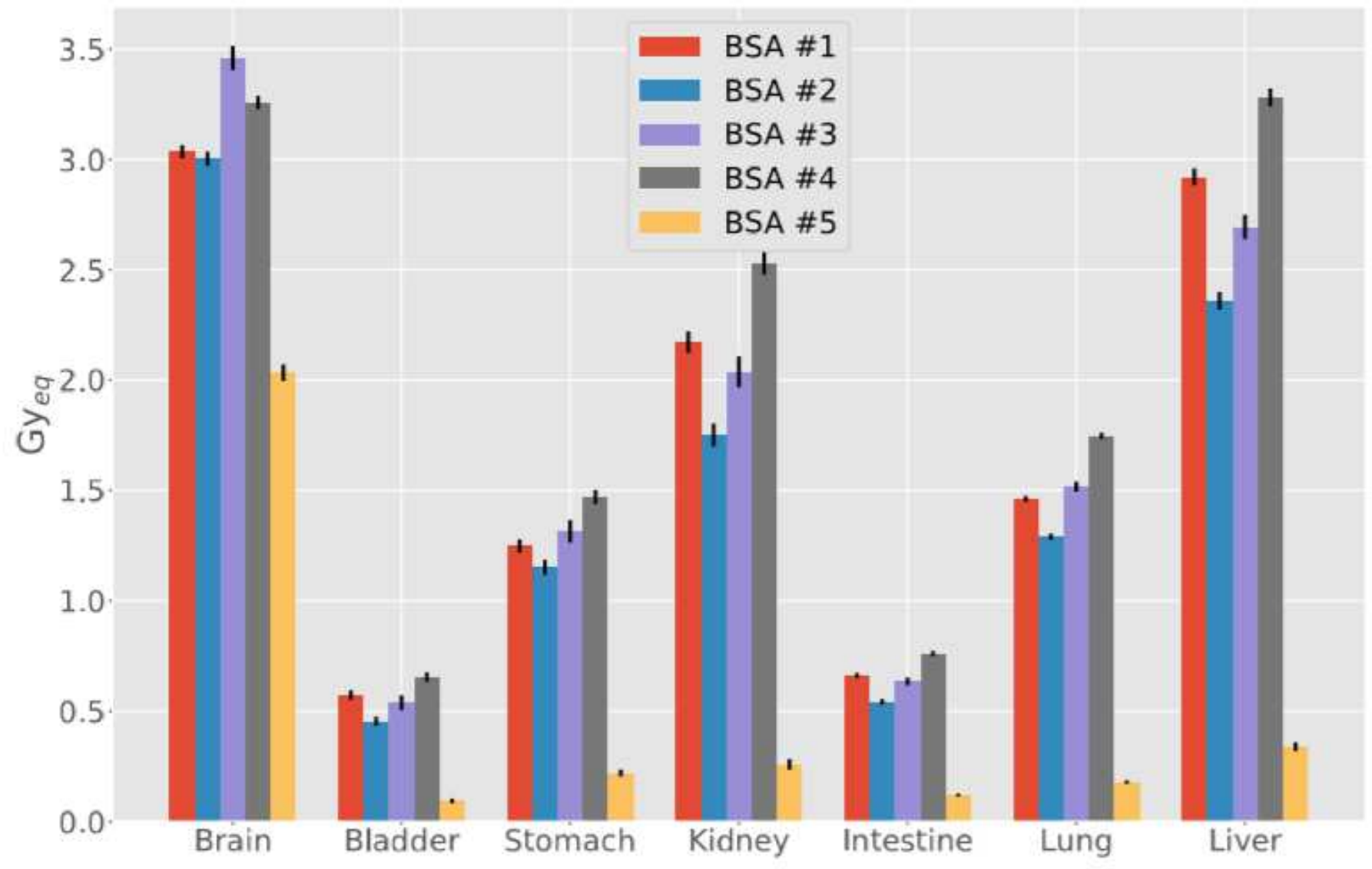

\section{Figure 5}

Comparison of out-of-beam dose evaluated in the MIRD phantom. Dose is evaluated for the treatment time, which is: 10 minutes for BSA \#1, 12.5 minutes for BSA \#2, 20 minutes for BSA \#3, 9.5 minutes for BSA \#4 and 24.5 minutes for BSA \#5.

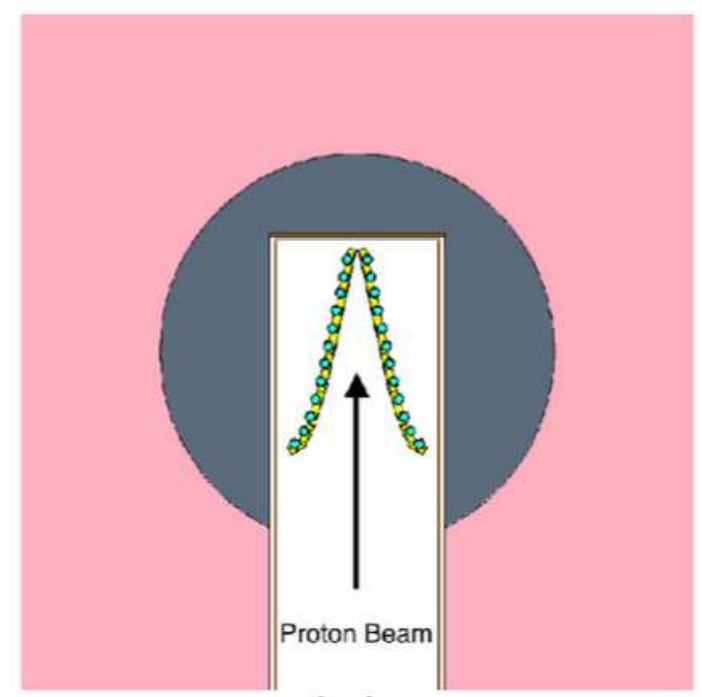

(a)

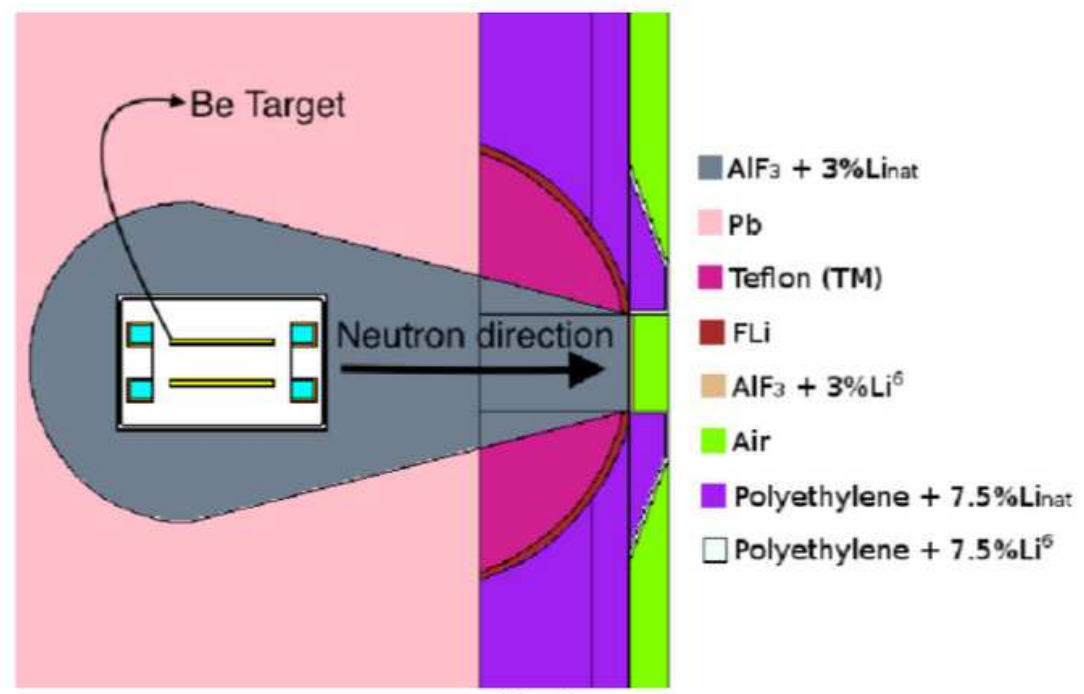

(b) 


\section{Figure 6}

Geometrical configuration of the final BSA, the different colours represent the material composition of the BSA. Left: xy plane: the proton beam hits the target in the $z$ direction. Right: $x z$ plane. The target has a Vshape, to keep a compact design while removing the total heat generated [14].

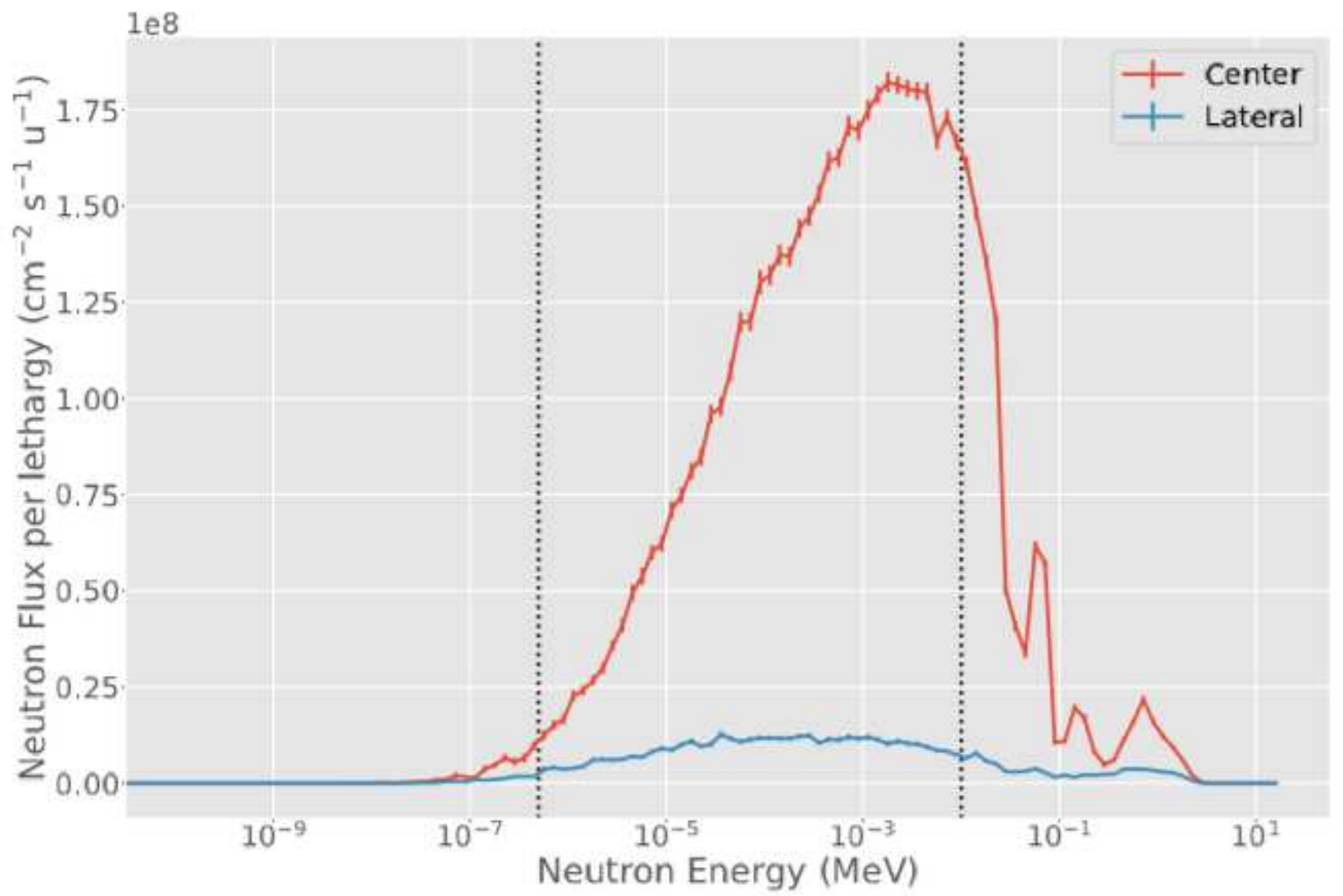

Figure 7

Final BSA energy spectra at the surface of the beam-port. Blue line: energy spectrum in a $6 \mathrm{~cm}$ radius disk, corresponding to the beam-port. Yellow line: spectrum in a ring with minimum radius of $6 \mathrm{~cm}$ and maximum radius of $12 \mathrm{~cm}$. The two vertical dotted lines separate thermal from epithermal energy ranges (5. 10-7 MeV) and epithermal from fast energy ranges (10-2 MeV). 

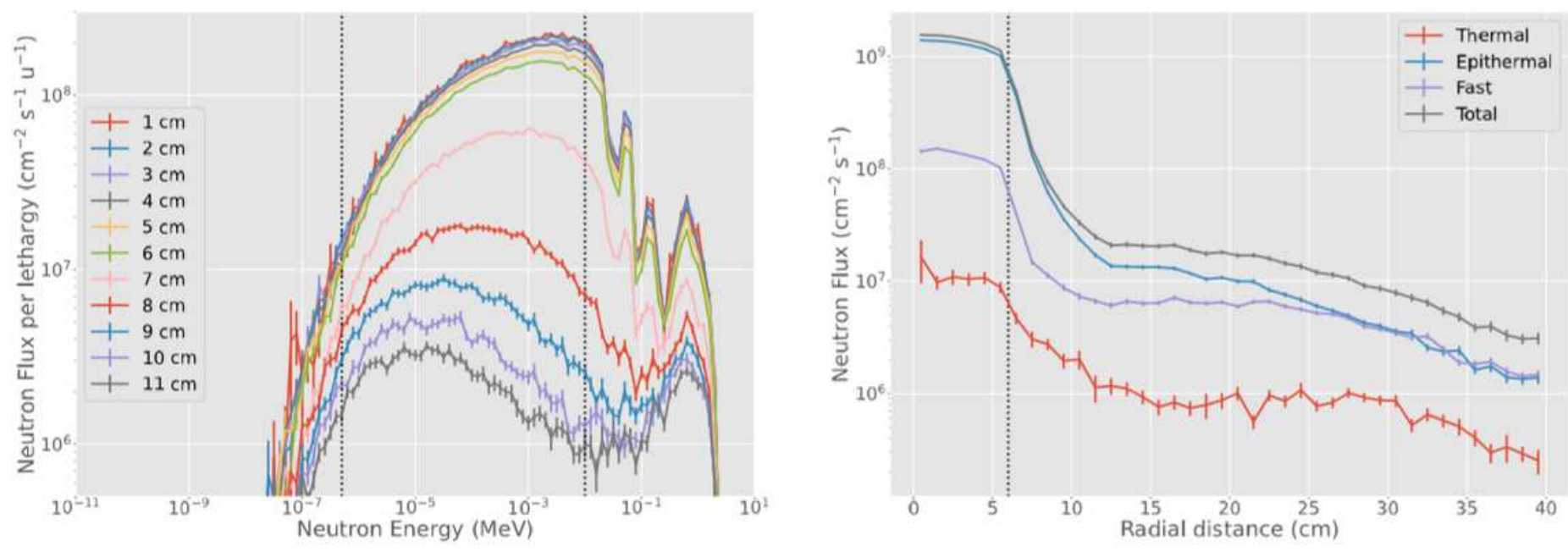

Figure 8

Neutron flux and energy spectra at the beam-port for BSA \#5. a) neutron spectra in concentric rings, with radii increasing by $1 \mathrm{~cm}$. The two vertical dotted lines separate thermal from epithermal energy ranges (5. 10-7 MeV) and epithermal from fast energy ranges (10-2 MeV). b) radial neutron flux distribution from the centre of the beam-port in concentric rings going from $0 \mathrm{~cm}$ to $40 \mathrm{~cm}$ of radius. The vertical dotted line delimits the beam-port radius. Blue: thermal neutron flux $(E \leq 5 \cdot 10-7 \mathrm{MeV})$, orange: epithermal flux (5. 10-7 MeV < E $\leq 10-2 \mathrm{MeV})$, green: fast flux $(10-2 \mathrm{MeV}<\mathrm{E})$ and red: total neutron flux. 


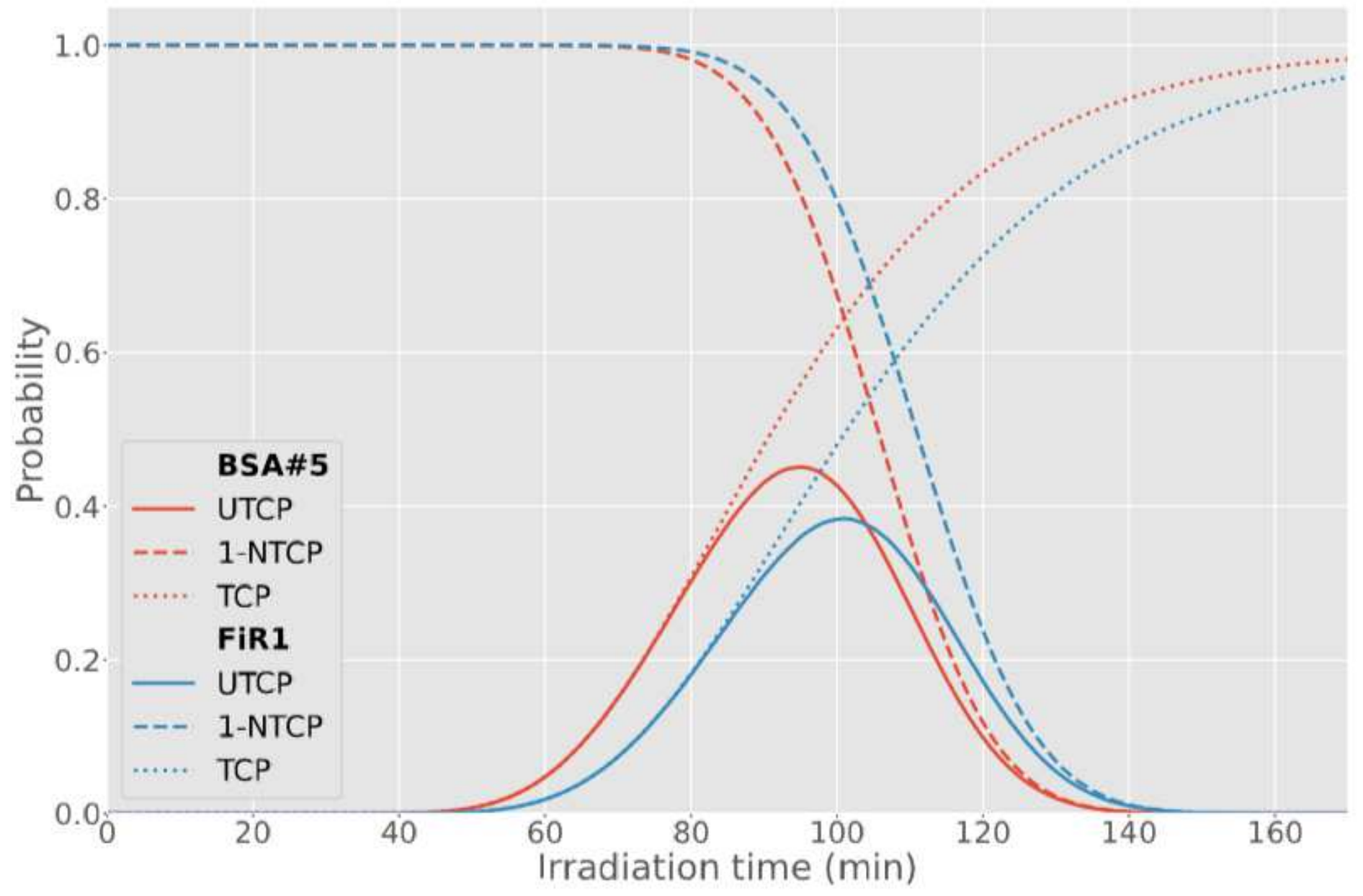

Figure 9

Comparison of the UTCP value for BSA \#5 and FiR 1 as a function of the irradiation time. 


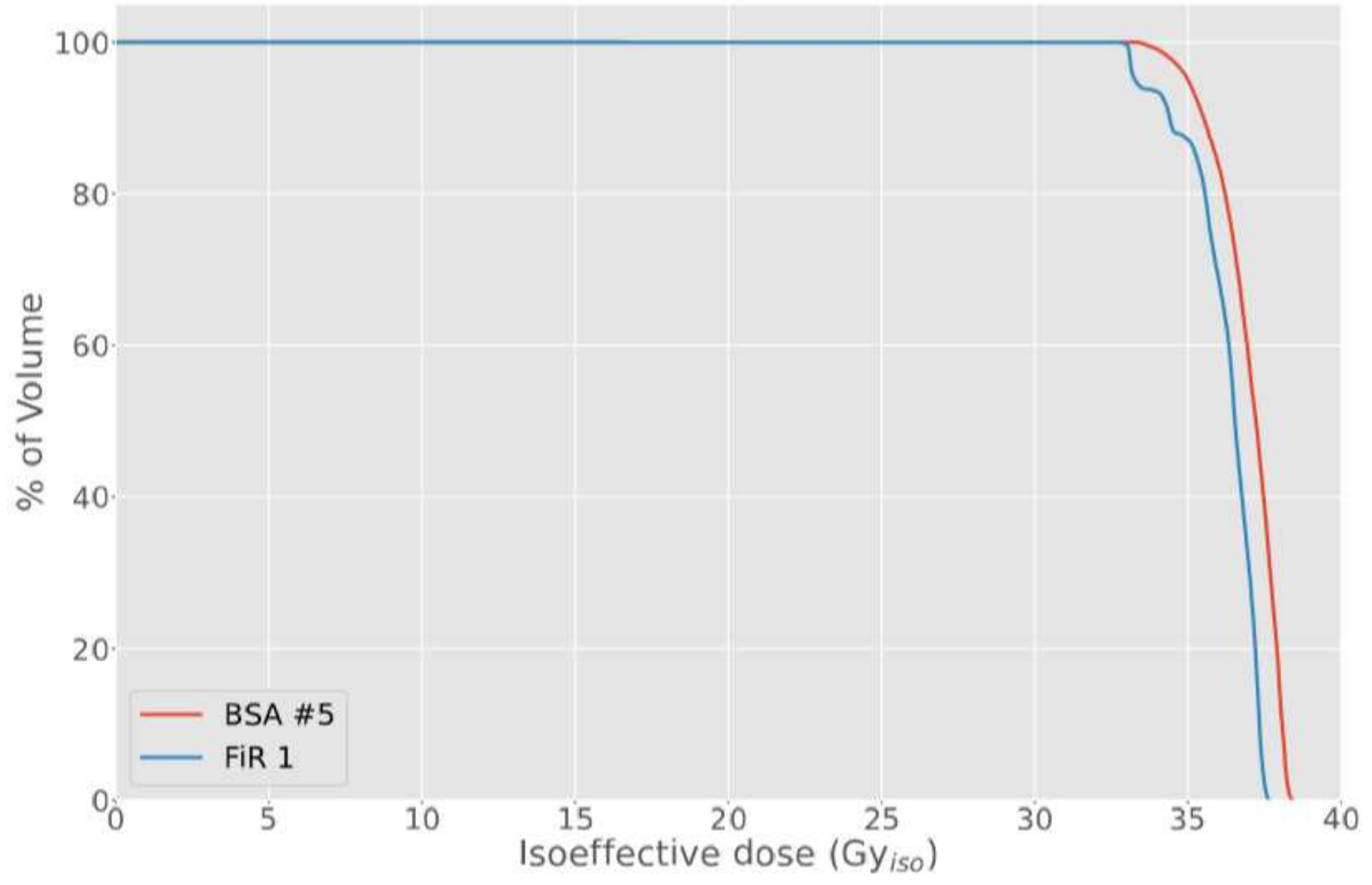

Figure 10

Comparison of the DVH obtained with BSA \#5 and FiR 1. 


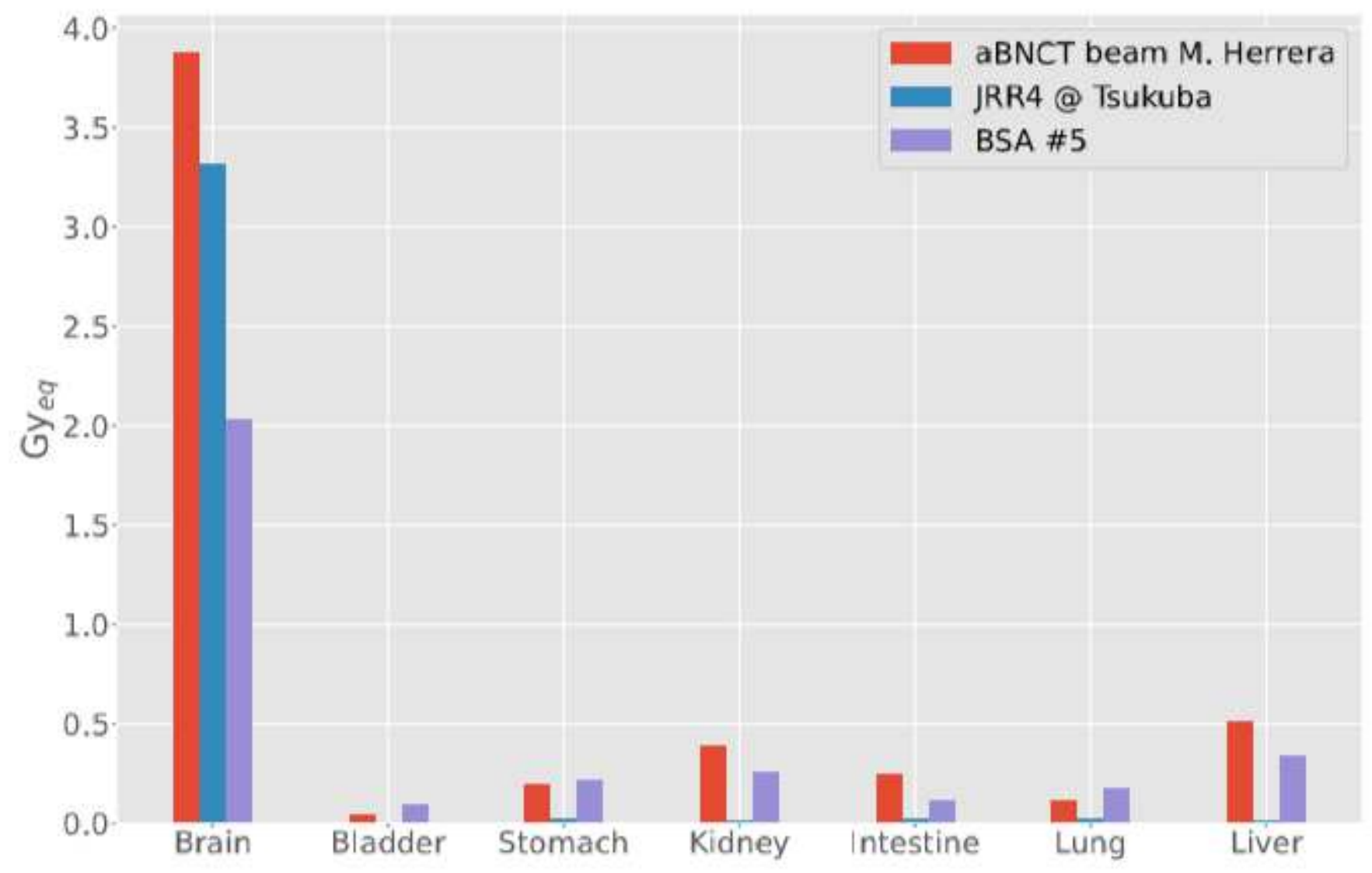

Figure 11

Out-of-beam dose evaluated in the MIRD phantom with BSA \#5, with a clinical reactor beam (JRR4) and with the ab-BNCT neutron beam designed by Herrera starting for $2.7 \mathrm{MeV}$ protons coupled with Li target [49]. 